\title{
CLM-FruitTree: A new sub-model for deciduous fruit trees in the Community Land Model (CLM5)
}

\author{
Olga Dombrowski ${ }^{1}$, Cosimo Brogi $^{1}$, Harrie-Jan Hendricks Franssen ${ }^{1}$, Damiano Zanotelli ${ }^{2}$, Heye Bogena ${ }^{1}$ \\ ${ }^{1}$ Agrosphere (IBG-3), Forschungszentrum Jülich GmbH, Jülich, 52425, Germany \\ $5 \quad{ }^{2}$ Faculty of Science and Technology, Free University of Bolzano, Bolzano, 39100, Italy
}

Correspondence to: Olga Dombrowski (o.dombrowski@fz-juelich.de)

\begin{abstract}
The inclusion of perennial, woody crops in land surface models is crucial to address their role in carbon (C) sequestration, food production, and water requirements under climate change. To help quantifying the biogeochemical and biogeophysical processes associated with these agro-ecosystems, we developed and tested a new sub-model, CLM-FruitTree,

10 for deciduous fruit orchards within the framework of the Community Land Model version 5 (CLM5). The model development included (1) a new perennial crop phenology description, (2) an adapted $\mathrm{C}$ and nitrogen allocation scheme, considering both storage and photosynthetic growth of annual and perennial plant organs, (3) typical management practices associated with fruit orchards, and (4) the parameterization of an apple plant functional type. CLM-FruitTree was tested using extensive field measurements from an apple orchard in South Tyrol, Italy. Growth and partitioning of biomass to the individual plant 15 components was well represented by CLM-FruitTree and average yield was predicted within $2.3 \%$ of the observed values despite low simulated inter-annual variability compared to observations. The simulated seasonal course of $\mathrm{C}$, energy, and water fluxes was in good agreement with the EC measurements owing to the accurate representation of the prolonged growing season and typical leaf area development of the orchard. We found that gross primary production, net radiation, and latent heat flux were highly correlated $(r>0.94)$ with EC measurements and showed little bias $(< \pm 5 \%)$. Simulated respiration components,

20 sensible heat, and ground heat flux were less consistent with observations. This was attributed to simplifications in the orchard structure and to the presence of additional management practices that are not yet represented in CLM-FruitTree. Finally, the results suggested that the representation of microbial and autotrophic respiration, and energy partitioning in complex, heterogeneous canopies in CLM5 requires further attention. The new sub-model CLM-FruitTree improved the representation of agricultural systems in CLM5 and can be used to study land surface processes in fruit orchards at the local, regional or
\end{abstract} 25 larger scale. 
https://doi.org/10.5194/gmd-2022-41

Preprint. Discussion started: 16 February 2022

(c) Author(s) 2022. CC BY 4.0 License.

\section{(c) (i)}

\section{Introduction}

Orchards and other perennial fruit crops are a major component of the global agricultural production with significant coverage

30 and yield in China, the United States, south-western Africa, and some parts of Europe (Fao, 2021). In the European region, perennial crops are a key economic element of Mediterranean agro-ecosystems as they provide $45 \%$ of the local agricultural output (Lobianco and Roberto, 2006). Apples are the most important fruit tree crop as one third of European orchards is devoted to their production. With a coverage of 984 '509 ha, they provide a yearly harvest of over 17 million tons which is one fifth of the overall European fruit production in terms of output value (Fao, 2021).

35 In contrast to annual crops, fruit trees can be productive for several decades before rotation is needed. Their prolonged growing season, standing biomass, and low respiratory losses can support carbon (C) storage and promote higher carbon use efficiencies (Wünsche and Lakso, 2000; Zanotelli et al., 2013). The transport of C stored in biomass into the soil in addition to reduced soil tillage and disturbances under fruit orchards compared to annual crops further promote C sequestration (Bwalya, 2012; Wu et al., 2012; Ledo et al., 2020). The FAO has therefore suggested perennial agriculture as a possible measure to mitigate climate change and enhance food security (Glover et al., 2010), and many studies have recently investigated this potential for various fruit orchards (Wu et al., 2012; Scandellari et al., 2016; Hammad et al., 2020; Yasin et al., 2021). The study of water and irrigation requirements in fruit orchards has become another field of intense research due to the need for a more resilient agriculture in the context of climate change and water supply shortages (Maestre-Valero et al., 2017; El Jaouhari et al., 2018; O'connell and Scalisi, 2019; Segovia-Cardozo et al., 2022). In order to answer questions related to C sequestration, water requirements, and sustainable food production of fruit orchards, a better understanding of the related ecosystem processes is vital (Fader et al., 2015).

Models with a comprehensive description of the carbon, water, and energy fluxes, such as global land surface models (LSMs), are a powerful tool to explore complex ecosystems like the abovementioned fruit orchards. The use of LSMs was recently extended to not only model the processes at the land-atmosphere interface, but also to study the response of ecosystems and water resources to climate change (Prentice et al., 2015; Fisher and Koven, 2020; Blyth et al., 2021). To quantify these effects, LSMs need to represent a wide range of land use and vegetation types. However, most LSMs consider only perennials such as deciduous and coniferous trees, as well as major annual crops such as wheat, soy, or maize (Lawrence et al., 2018). Recently, some LSMs additionally include bioenergy crops (Schaphoff et al., 2018), while others group crops into a few generic crop types (Noilhan and Mahfouf, 1996; Krinner et al., 2005; Balsamo et al., 2009). Despite their significance, perennial crops, such as fruit trees, are rarely considered in LSMs and attempts of including them in global and regional modelling environments are scarce (Fader et al., 2015; Cheng et al., 2020). An example of such an attempt is the inclusion of agricultural trees (e.g., grapes, cotton, and apple trees) in the Lund-Potsdam-Jena managed Land model to improve the representation of Mediterranean agro-ecosystems (Fader et al., 2015). Here, agricultural trees were modelled as small trees and fruit harvest was determined as the product of a plant specific harvest index and the net primary productivity (NPP). Other authors parameterized oil palm trees, a perennial evergreen crop, in the Community Land Model (CLM) version 4.5 (Fan et al., 2015). Palm trees 
were represented by a new phenology where large palm leaves with fruit bunches emerge successively, leaves are pruned regularly, and harvest occurs once a month. Recently, two perennial grasses for energy production were parameterized in the latest version of the model, CLM5 (Cheng et al., 2020). Parameters for bioenergy crops were tuned using sensitivity analysis and observations, while harvest was represented by removing around $70 \%$ of the aboveground biomass.

65 While the above-mentioned studies describe some common features of perennial plants, they do not, or only partially, represent the seasonal deciduous phenology of fruit trees or the explicit modelling of fruit growth. Furthermore, key aspects such as $\mathrm{C}$ reserve deposition and mobilization in the following spring are generally not considered, possibly due to necessary simplifications or because the drivers of these processes are still not fully understood (Le Roux et al., 2001; Neumann, 2020). The absence of perennial crops in land surface models introduces a significant bias in the representation of biogeophysical and

70 biogeochemical processes in agro-ecosystems where this type of cultivation is prevalent. As a result, the response to climate change in terms of $\mathrm{C}$ sequestration, water requirements, or food production cannot be assessed adequately in regions such as the Mediterranean, where perennial, woody crops are very common and play a vital role for food security and economy (Fader et al., 2015; Lobianco and Roberto, 2006).

Although deciduous fruit trees share certain characteristics with natural vegetation and annual crops in LSMs such as CLM5,

75 several particularities in their growth dynamics and management practices still prevent a meaningful simulation using currently available representations of vegetation. In this study, we therefore provide CLM5 with the ability of modelling perennial fruit trees and the associated processes. For this purpose, we developed a new sub-model named CLM-FruitTree within the existing model framework of CLM5. CLM-FruitTree combines elements of the broadleaf deciduous tree subroutine such as growth and $\mathrm{C}$ turnover of woody components, with distinctive phenological stages and a harvestable organ similar to the annual crop 80 subroutine. We first describe the model conceptualization including the new phenology, carbon and nitrogen $(\mathrm{CN})$ allocation, and management options. We further demonstrate the applicability of CLM-FruitTree by parameterizing a new apple plant functional type (PFT). Finally we evaluate and discuss the model performance using extensive field data from an apple orchard in South Tyrol, Italy.

\section{Methods}

\section{$85 \quad 2.1$ Vegetation characterizations in CLM5}

The latest version of the Community Land Model, CLM5, simulates the exchange of water, energy, C, and nitrogen (N) between land and atmosphere as well as their storage and transport on the land surface and in the subsurface, driven by climate variability and modulated by soil and vegetation states and characteristics. The land surface in CLM5 is characterized by one of five land units namely glacier, lake, urban, vegetated, and crop. These units are further divided to capture the variability in

90 soil, vegetation, and management options (i.e., irrigated or non-irrigated). Compared to previous model versions, CLM5 features various improvements in the representation of land use and vegetation modelling such as plant $\mathrm{CN}$ cycling, soil and plant hydrology and crop modelling (Lawrence et al., 2018). 
https://doi.org/10.5194/gmd-2022-41

Preprint. Discussion started: 16 February 2022

(c) Author(s) 2022. CC BY 4.0 License.

\section{(c) (i)}

The inclusion of the Biome-BGC (Biome BioGeochemical Cycles) model into CLM4 allowed the simulation of 15 different PFTs of natural, woody and non-woody, vegetation including broadleaf deciduous trees (BDT). The latter is described by an algorithm for the seasonal phenology of deciduous trees that controls changes in phenology, as well as the $\mathrm{C}$ and $\mathrm{N}$ fluxes between different plant and litter pools. Here, leaf onset and offset periods mark the beginning and end of a growing season. Once a new onset growth period is initiated, $\mathrm{C}$ and corresponding $\mathrm{N}$ fluxes occur out of a storage pool into a transfer pool (intermediate pool to separate fluxes in and out of the storage pool) from where they are gradually transferred to the displayed growth pool (Fig. 1). All plant organs are maintained separately in each of the three pools. During the active growth period, C and corresponding $\mathrm{N}$ storage pools of the individual plant organs are replenished based on fixed stoichiometric relationships and $\mathrm{C}: \mathrm{N}$ ratios of each plant organ. At leaf offset, $\mathrm{C}$ and $\mathrm{N}$ pools feed the litter or coarse woody debris pool, while others are retained as structural woody tissue.

In addition, CLM5 now features the Biogeochemistry Crop Module (BGC-crop), adopted from the prognostic crop module of the Agro-Ecosystem Integrated Biosphere Simulator (Agro-IBIS), which provides eight different annual crop species with interactive crop management options (i.e., irrigation and fertilization). Another 23 currently inactive crop types can be defined but have not been provided with specific crop parameters. Crop phenology and $\mathrm{CN}$ allocation follow three phenological phases: (1) from planting to leaf emergence, (2) from leaf emergence to the start of grain fill, and (3) from grain fill to grain mat urity and harvest, that are controlled by temperature and growing degree-day (GDD) thresholds. Different to natural vegetation, all assimilates are directed to the displayed pools while the storage pools remain unused. At harvest, $\mathrm{C}$ and $\mathrm{N}$ from the grain pool are transferred to a grain product pool while a small amount is kept to reseed the crop in the following year. All remaining plant parts feed the litter cycle (Fig. 1). The reader is referred to the technical documentation of CLM5 for a more detailed description of the vegetation and crop description (Lawrence et al., 2018).

From the above description of the existing model components, the following limitations for the application of CLM5 to deciduous fruit trees arise: (1) the current CLM-BGC-crop algorithm does not allow the simulation of perennial and/or woody crops; (2) the seasonal deciduous phenology algorithm although describing some characteristics common to fruit trees, lacks the capability of simulating a harvestable organ, independent development of different plant parts, and active growth in the current season; (3) typical management practices of fruit orchards such as transplanting of tree seedlings and pruning are currently not represented in CLM5; and (4) there is no parameterized fruit tree PFT in the default parameter set of CLM5.

\subsection{Model conceptualization}

120 To resolve the model limitations discussed in Sect. 2.1, we have developed a new sub-model CLM-FruitTree to model growth and yield of deciduous fruit trees grown in orchard systems as well as the associated ecosystem processes. More specifically, for the implementation of CLM-FruitTree, we introduced a new phenology subroutine including crop management options next to the existing subroutines of natural vegetation and crops. In addition, the $\mathrm{CN}$ allocation module as well as corresponding modules (including $\mathrm{C}$ and $\mathrm{N}$ state and flux updates, vegetation structure, and respiration) were modified. The modification of sub-routines and creation of new parameters followed CLM5 standards and the given model structure. Where necessary, new 
history and restart variables were added to restart simulations with bit-for-bit continuity of the output (Lawrence et al., 2018). Furthermore, to test the new sub-model, an apple PFT was parameterized and added to the active crops using one of the existing but currently inactive crop types in CLM5, type 35 and 36 (rain fed and irrigated citrus).

CLM-FruitTree combines characteristics of both BDT and annual crops to simulate a perennial woody crop with a harvestable organ (Fig. 1). Similar to the existing BDT phenology algorithm in CLM5, the fruit tree algorithm uses a perennial deciduous phenology with standing woody biomass and annual leaf shedding. During the active growth period however, the phenology and $\mathrm{CN}$ allocation of vegetative and harvestable organs are described by distinct growth phases and are driven by a GDD summation similar to the crop phenology.

An orchard is established by transplanting small tree seedlings from nursery, a typical planting method for this type of 135 cultivation (Wheaton et al., 1990; Corelli-Grappadelli and Marini, 2008). Once planted, the orchard remains productive for 25-40 years as defined by the user. In CLM-FruitTree, both stored C and current photosynthesis contribute to growth of the fruit tree, as leaf and shoot development at the beginning of a growing season utilize carbohydrate reserves and nitrogenous compounds that were accumulated during the previous season (Tromp, 1983; Oliveira and Priestley, 1988; Loescher et al., 1990). Deciduous fruit trees are dormant in winter and resume growth in spring after meeting species- and cultivar-specific 140 chilling and heat requirements (Anderson et al., 1985; Faust et al., 1997; Zavalloni et al., 2006), which is represented in CLMFruitTree using the chilling and forcing model suggested by Cesaraccio et al. (2004). Early in the season, the canopy develops rapidly until it reaches maturity typically by midsummer, while leaf shedding occurs when temperatures drop in autumn (Kozlowski, 1992; Loescher et al., 1990; Lakso et al., 1999). Fruit trees usually start flowering 3-4 weeks after bud burst, which is not specifically represented by CLM-FruitTree which instead assumes that fruit growth begins after full bloom (Lakso

145 et al., 1999). Fruit growth is described by two stages, cell division and cell expansion that together form a sigmoid growth curve for many fruit tree species such as apple, pear, and orange (Corelli-Grappadelli and Lakso, 2002; Jackson, 2011).

In the following, the new developments to account for the distinct phenology, $\mathrm{CN}$ allocation, and management practices of a fruit orchard are described in more detail. Other biochemical and biophysical processes such as photosynthesis, water and litter cycles, and fixation and uptake of $\mathrm{N}$ were not modified except for minor adaptations to the retranslocation of $\mathrm{N}$ and respiration. 
https://doi.org/10.5194/gmd-2022-41

Preprint. Discussion started: 16 February 2022

(c) Author(s) 2022. CC BY 4.0 License.

(c) (1)

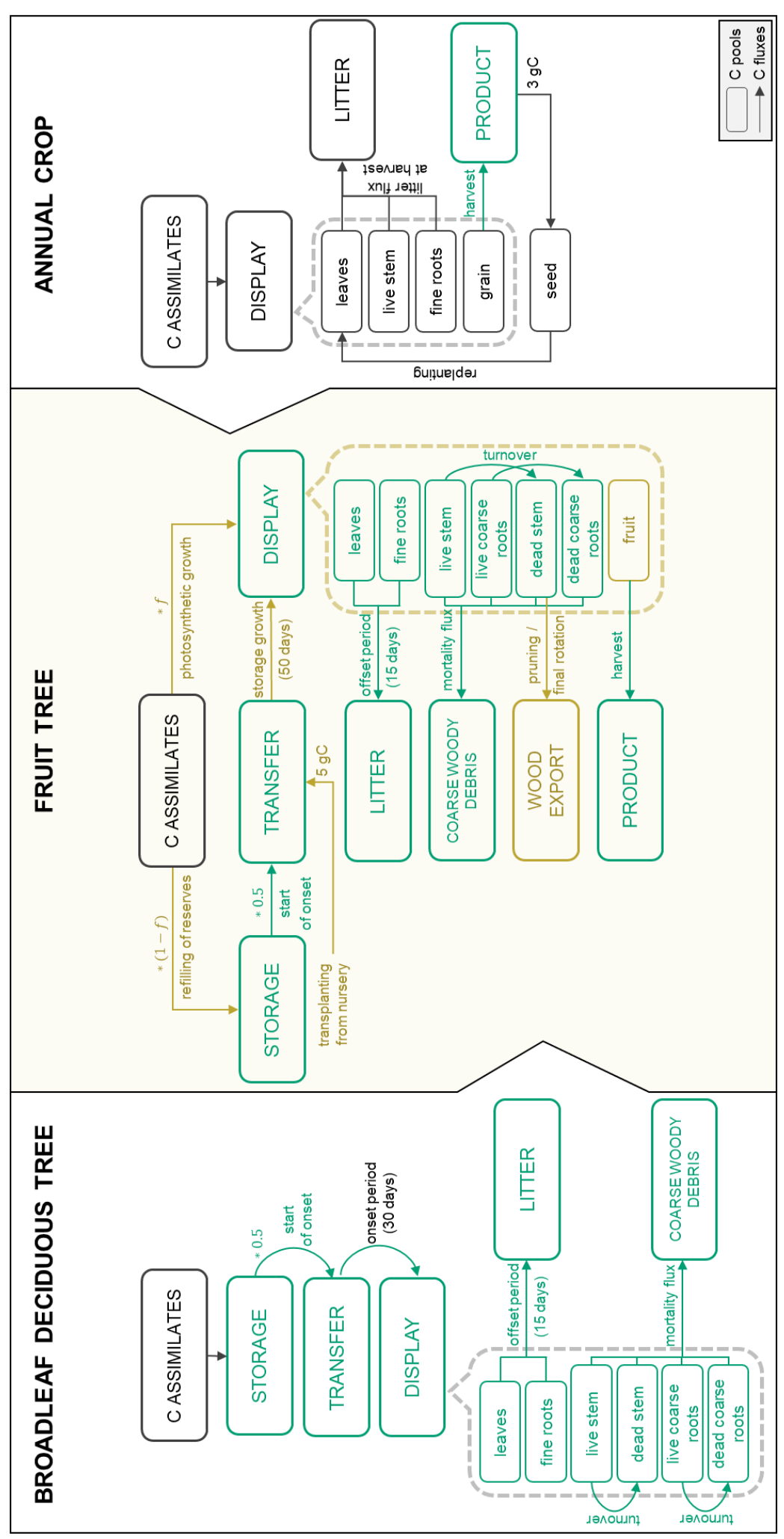

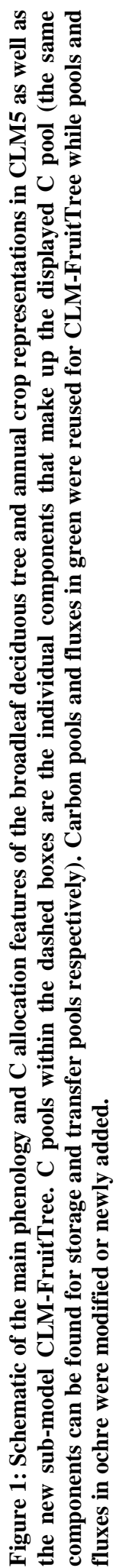




\subsubsection{Phenology}

A new orchard lifecycle is initialized by transplanting seedlings at the beginning of the year during dormancy. An initial biomass of $5 \mathrm{gC} \mathrm{m}^{-2}$ is assigned to leaf and fine root transfer pools, and $0.5 \mathrm{gC} \mathrm{m}^{-2}$ is assigned to the dead stem pool. Each pool is also assigned the corresponding amount of $\mathrm{N}$. Apple growth thereafter is described by six post-planting phenological stages, namely: (1) bud break, (2) fruit growth, (3) fruit ripening, (4) canopy maturity, (5) fruit maturity and harvest, and (6) start of leaf senescence (Fig. 2).

Bud break is predicted by a sequential model that first accumulates chill days followed by anti-chill days based on a predefined temperature threshold and chilling requirement (Cesaraccio et al., 2004). More information on the sequential model and the calibration of model parameters can be found in Appendix A. At bud break, a portion of the $\mathrm{C}$ in the storage pool of all plant components, except fruits, is transferred to the actively growing $\mathrm{C}$ pools over a period of 50 days as controlled by the newly added parameter ndays_stor. Outside the dormant period, leaf and fruit development occur independently as fruit growth typically starts 4-5 weeks after bud break while canopy development continues until mid-season and leaf senescence does not occur until after the fruits are harvested (Wünsche and Lakso, 2000; Goldschmidt and Lakso, 2005) (Fig. 2).

The thermal thresholds to reach phases (2)-(5) (Appendix C) are defined as accumulated GDDs since bud break. GDDs are determined as the difference between the average daily air temperature and a base temperature of $4{ }^{\circ} \mathrm{C}$ with a maximum daily increment of $26^{\circ}$ days (Eq. (1)). Different to the existing deciduous phenology, leaf senescence is triggered not by day length but by the drop of the daily mean temperature below a critical temperature threshold, in this case the base temperature. This approach was selected since many fruit trees that belong to the Rosaceae family (e.g., apple, pear, plum, and cherry) are unaffected by photoperiod and instead controlled by temperature (Heide and Prestrud, 2005). The last day of the leaf-offset period marks the beginning of dormancy. The new phenology subroutine of CLM-FruitTree also controls C reserve dynamics, stem and root turnover, and final rotation, which involves removing and replanting trees when the maximum orchard lifespan is reached.

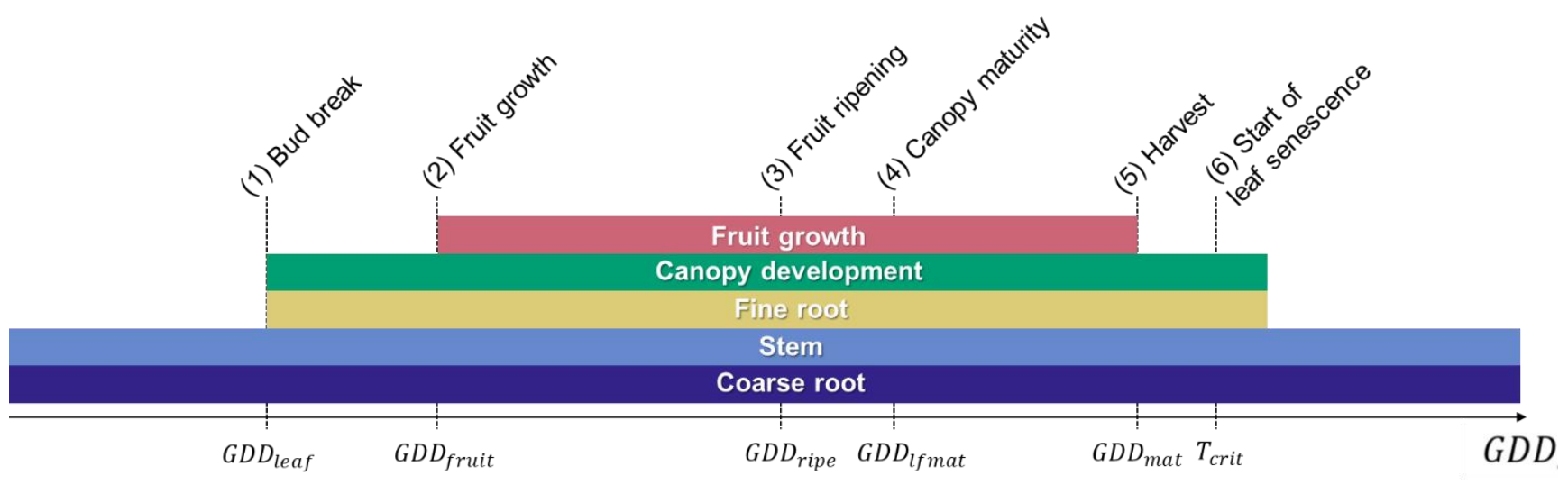

Figure 2: Fruit tree phenological stages of (1) bud break at the end of dormancy, (2) the start of fruit growth, (3) fruit ripening, (4) canopy maturity, (5) harvest, and (6) the start of leaf senescence. The lengths of phenological stages (2)-(5) are determined by their 
180 respective growing degree-day thresholds (GDD) starting from bud break (GDD leaf=0), while stage (6) is determined by a critical temperature threshold $\left(\mathbf{T}_{\text {crit }}\right)$.

\subsubsection{Carbon and nitrogen allocation}

$\mathrm{CN}$ allocation to the growth of new tissue (display pools) and to storage pools follows the phenological stages described in Sect. 2.2.1 (Fig. 2). A coupled CN allocation subroutine determines the fate of newly assimilated C from photosynthesis. The potential allocation to the different plant components is based on allocation coefficients and allometric relationships between dead and alive parts of stem and coarse root. Throughout the growing period until harvest, $5 \%$ of the newly assimilated C is allocated to the storage pools, as defined by the $f c u r$ parameter. The remainder is allocated to the displayed C pools except for fruits where all allocated $\mathrm{C}$ is assigned to the displayed pool.

Before the start of fruit growth, phase (1), available $\mathrm{C}$ and $\mathrm{N}$ are partitioned between leaves, stem and root pools. The allocation coefficients are calculated according to a set of equations that were adapted from the AgroIBIS crop phenology algorithm used in CLM5-BGC-crop (Lawrence et al., 2018):

$$
\begin{aligned}
& G D D_{T 2 m}=G D D_{T 2 m}+T_{2 m}-T_{f}-4 \quad \text { where } \quad 0 \leq T_{2 m}-T_{f}-4 \leq 26^{\circ} \text { days, } \\
& a_{\text {repr }}=0 \\
& a_{\text {froot }}=a_{\text {froot }}^{i}-\left(a_{\text {froot }}^{i}-a_{\text {froot }}^{f}\right) * \frac{G D D_{T 2 m}-G D D_{\text {leaf }}}{G D D_{\text {fruit }}-G D D_{\text {leaf }}}, \\
& a_{\text {leaf }}=\left(1-a_{\text {froot }}\right) * \frac{a_{\text {leaf }}^{i}\left(e^{-b_{-}} e^{\left.-b * \frac{G D D_{T 2 m}-G D D_{\text {leaf }}}{G D D_{\text {lfmat }}-G D D_{\text {leaf }}}\right)}\right.}{e^{-b_{-1}}}, \\
& a_{\text {livestem }}=1-a_{\text {repr }}-a_{\text {froot }}-a_{\text {leaf }},
\end{aligned}
$$

where $G D D_{T 2 m}$ are the accumulated growing degree-days for the 2-m air temperature with maximum increments of $26^{\circ}$ days; $T_{2 m}$ is the simulated 2-m air temperature in $\mathrm{K} ; T_{f}$ is the freezing temperature of water and equals $273.15 \mathrm{~K} ; G D D_{\text {leaf }}$, $G D D_{\text {fruit }}$, and $G D D_{\text {lfmat }}$ are thermal thresholds for bud break, start of fruit growth, and canopy maturity, respectively; $b$ is an exponential factor; $a_{\text {leaf }}^{i}, a_{\text {froot }}^{i}$, and $a_{\text {froot }}^{f}$ are initial and final values for the allocation coefficients to leaf $\left(a_{\text {leaf }}\right)$ and fine root $\left(a_{\text {froot }}\right)$, respectively; and $a_{\text {repr }}$ and $a_{\text {livestem }}$ are the allocation coefficients to fruit and live stem, respectively. 
Once fruit growth begins in phase (2), an increasing proportion of the assimilated C is allocated to this organ, causing leaf allocation to decline and fruit allocation to plateau at a high value once canopy maturity is reached. Fine roots and stem continue to decline and then settle at a constant value until harvest.

$$
\begin{aligned}
& a_{\text {livestem }}=a_{\text {livestem }} *\left(1-\frac{\left(G D D_{T 2 m}-G D D_{\text {leaf }}\right)-\left(G D D_{\text {fruit }}-G D D_{\text {leaf }}\right)}{\left(G D D_{\text {mat }}-G D D_{\text {leaf }}\right)^{d_{L}-\left(G D D_{\text {fruit }}-G D D_{\text {leaf }}\right)}}\right)^{d_{\text {alloc }}^{\text {stem }}}, \\
& a_{\text {repr }}=1-a_{\text {froot }}-a_{\text {livestem }}-a_{\text {leaf }},
\end{aligned}
$$

where $G D D_{\text {mat }}$ is the thermal threshold for fruit maturity and harvest, while $d_{L}$ and $d_{\text {alloc }}^{\text {stem }}$ are stem allocation decline factors.

After harvest and until the start of dormancy, all of the newly assimilated $\mathrm{C}$ is sent to the storage pools following the notion that late in the season, assimilates are used mostly to fill up reserves that can be mobilized to resume growth in the following spring (Le Roux et al., 2001). Fruit trees store $\mathrm{C}$ in the perennial woody parts of the tree from where it is remobilized to support the growth of new shoots, leaves, and fine roots (Oliveira and Priestley, 1988; Millard, 1996; Le Roux et al., 2001). Since in CLM5 separate storage pools are assigned to each plant organ, the newly added aleafstor parameter (Table C1) defines the fraction of allocatable $\mathrm{C}$ going to the leaf storage pool while the remainder is split equally between roots and stem.

\subsubsection{Parameterization of other processes and management practices}

210 Fruit trees, similar to other deciduous species, have been observed to translocate $\mathrm{N}$ out of senescent leaves to be reused by other tree organs (Murneek, 1942; Bollard, 1960). Therefore, CLM-FruitTree adopts the same N retranslocation strategy as used in the BDT phenology (Lawrence et al., 2018). Furthermore, management practices such as fertilization and stem pruning are represented in the new sub-model. Fertilization is performed on a yearly basis after the occurrence of bud break, as $\mathrm{N}$ fertilization in early spring is still the most common practice in fruit orchards even though autumn fertilization or multiple applications via fertigation are also in use to increase fertilizer $\mathrm{N}$ use efficiency and reduce $\mathrm{N}$ losses (Sanchez et al., 1995; Carranca et al., 2018). We use the existing fertilization scheme of the crop phenology that adds fertilizer directly to the soil mineral $\mathrm{N}$ pool. A user-defined fertilization rate or amount can be applied as synthetic fertilizer or manure respectively, although there currently is no difference in model behaviour for these two fertilizer types (Lawrence et al., 2018).

Pruning is performed as the tree enters dormancy by removing a user-defined fraction, prune_fr (Table $\mathrm{C} 1$ ), of the dead stem from both storage and displayed C pools. Pruning residues are treated in one of two ways: (1) residues are added to the wood harvest pool and exported from the field or (2) residues are mulched into the soil thus feeding the litter cycle. The former is typically adopted in conventional agriculture were residues are exported and treated as waste (Benyei et al., 2018) or utilized for energy production (Kazimierski et al., 2021). The latter is more common in orchards under organic production to increase C sequestration in soils (Montanaro et al., 2010; Aguilera et al., 2015). During the first three years after planting, trees are not pruned to allow some initial stem biomass to grow. In practice, winter pruning in fruit orchards may be performed throughout 
the winter to control the shape and size of fruit trees, and partially to manage crop load (Grechi et al., 2008). The pruning implemented in CLM-FruitTree affects only the dead stem biomass and tree height that is calculated based on this biomass pool, which in turn effects the calculation of turbulent fluxes of sensible and latent heat. However, this effect is small, and since turbulent fluxes are generally low in winter, the exact timing of pruning does not play a significant role in the magnitude of these fluxes. When the orchard reaches the end of its lifespan, $\mathrm{C}$ of all biomass pools (storage, transfer, and display) is sent to either the litter pool for leaves and fine roots, or the wood harvest pool for live and dead stem and coarse roots while any remaining $\mathrm{C}$ in the fruit pool is harvested. The orchard can then be replanted in the following year. Lastly, the standard irrigation routine implemented in CLM5 can be used for irrigated orchards by selecting the irrigated crop PFT.

\subsection{Model implementation and testing}

\subsubsection{Site data}

Extensive field measurements from an apple-growing region in the Adige River valley, South Tyrol, Italy $\left(46^{\circ} 21^{\prime} \mathrm{N}, 11^{\circ} 16^{\prime}\right.$ E; $240 \mathrm{~m}$ a.s.l.) were used to parameterize and test the new sub-model CLM-FruitTree along with the new apple PFT (Zanotelli et al., 2013; Zanotelli et al., 2015; Zanotelli et al., 2019). Measurements were obtained from an approximately 0.5 ha irrigated apple orchard planted in 2000 with the Fuji apple cultivar grafted on M9 dwarfing rootstock. The apple trees were planted at

240 a row and tree spacing of $3 \times 1 \mathrm{~m}$ (3333 trees ha-1). A $1.8 \mathrm{~m}$ wide grass strip was grown between the tree rows, which was mowed 3 times a year. Other management practices included regular pruning, spring fertilization of $7.5 \mathrm{gN} \mathrm{m}^{-2} \mathrm{yr}^{-1}$, and tillage of the soil directly underneath the trees (Zanotelli et al., 2013). Stand-related data included general stand characteristics and phenology observations, leaf area index, C:N ratios, rooting distribution at three depth ranges $(0-20 \mathrm{~cm}, 20-40 \mathrm{~cm}$, and 40 $60 \mathrm{~cm}$ ), measurements of the biomass growth of different tree organs at monthly or seasonal interval, and fruit harvest

245 information (Table 1). Furthermore, daily soil respiration measurements from a control and a trenching plot (with $\left(R_{s}\right)$ and without root respiration $\left(\mathrm{R}_{\mathrm{h}}\right)$, respectively) were performed in 2010. Additionally, an eddy covariance (EC) station provided measurements of the turbulent exchange of trace gases and energy at the studied apple orchard between 2013 and 2015. The quality check, gap filling, and flux partitioning of collected data followed the procedure outlined in Reichstein et al. (2005). The average closure of the energy balance was $60 \%$. To correct for the closure failure, the missing energy was assigned to the latent (LE) and sensible (H) heat fluxes based on the daily Bowen ratio (Zanotelli et al., 2019). Measured or derived fluxes included net ecosystem $\mathrm{CO}_{2}$ exchange (NEE), ecosystem respiration ( $\mathrm{R}_{\mathrm{eco}}$ ), gross primary production (GPP), LE, $\mathrm{H}$, and evapotranspiration (ET) at half-hourly intervals. Furthermore, soil heat flux $(\mathrm{G})$ measured at $5 \mathrm{~cm}$ depth as well as soil moisture measurements up to a depth of $60 \mathrm{~cm}$ of soil are available. Table 1 gives a summary of the available data and measurement periods. A complete description of the measurement procedures and instruments can be found in Zanotelli et al. (2013), 255 Zanotelli et al. (2015), and Zanotelli et al. (2019).

Meteorological data, recorded partly at the EC tower and at the Laimburg meteorological station located $4 \mathrm{~km}$ from the site $\left(46^{\circ} 23^{\prime} \mathrm{N}, 11^{\circ} 17^{\prime} \mathrm{E} ; 224 \mathrm{~m}\right.$ a.s.1.), were used at an hourly time step to force the model. Measured data included precipitation, 
solar radiation, net radiation ( $\mathrm{R}_{\mathrm{n}}$, only at $\mathrm{EC}$ tower), air temperature, air pressure (only at Laimburg), relative humidity, and wind speed. Measurements of incoming longwave radiation $\left(\mathrm{LW}_{\text {in }}\right)$ were available for 2010 only, but additional calculations following Konzelmann et al. (1994) and Sedlar and Hock (2009) were produced and used as forcing for the remaining years 2011-2019 (Appendix B). This was necessary since the use of the internally calculated LW $\mathrm{W}_{\text {in }}$ in CLM5 resulted in unrealistic underestimations compared to the available measurements of $\mathrm{LW}_{\text {in }}$ leading to a significant bias in $\mathrm{R}_{\mathrm{n}}$.

Table 1: Summary of available data from an apple orchard in the Adige River valley, South Tyrol, Italy between 2010 and 2019. Solid lines represent continuous, dotted lines monthly measurements, and diamonds represent single measurements.

\begin{tabular}{|c|c|c|c|c|c|c|c|c|c|c|}
\hline Data & 2010 & 2011 & 2012 & 2013 & 2014 & 2015 & 2016 & 2017 & 2018 & 2019 \\
\hline \multicolumn{11}{|l|}{ Weather data EC tower } \\
\hline \multicolumn{11}{|l|}{ Weather data Laimburg } \\
\hline Biomass (NPP) components & $\bullet \cdots \cdots$ & ? & s & 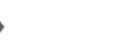 & & & & & & \\
\hline $\mathrm{C}: \mathrm{N}$ ratios of biomass components & $\bullet \cdots \cdots$ & & & & & & & & & \\
\hline Leaf area index (LAI) & $\cdots \cdots$ & $\cdots \cdots$ & $\cdots \cdots$ & & & & & & & \\
\hline Fruit production (yield) & - & r & 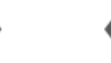 & - & • & - & & & & \\
\hline Root distribution $(0-60 \mathrm{~cm})$ & • & & & & & & & & & \\
\hline \multicolumn{11}{|l|}{ Soil respiration $\left(\mathrm{R}_{\mathrm{s}}, \mathrm{Rh}_{\mathrm{h}}\right)$} \\
\hline \multicolumn{11}{|l|}{ Soil heat flux (G) } \\
\hline \multicolumn{11}{|l|}{ Soil water content $(\mathrm{SWC}, 0-60 \mathrm{~cm})$} \\
\hline $\begin{array}{l}\text { EC data: carbon (GPP, Reco, NEE), } \\
\text { energy }\left(R_{n}, L E, H\right) \text {, water }(E T)\end{array}$ & & & & & & & & & & \\
\hline
\end{tabular}

\subsubsection{Model setup}

The model was set up in point mode to simulate the apple orchard in the Adige valley using available sand, clay, and organic matter fractions. The model was spun-up for 200 years, first in accelerated decomposition and then in normal decomposition mode, until all state variables, such as total ecosystem soil C and soil water, reached equilibrium (Lawrence et al., 2018). For the model spin-up, the CRUNCEPv7 atmospheric forcing data set from 1986 to 2016 was used (Viovy, 2018). The apple orchard was then initiated using the newly developed sub-model and the apple PFT selecting the site-specific management (i.e., fertilization with $7.5 \mathrm{gN} \mathrm{m}^{-2} \mathrm{yr}^{-1}$, irrigation, mulching of pruning material). Simulations were performed for a period of 10 years to mirror the time from orchard establishment in 2000 up to the start of the measurements in 2010 using 10 years (2010-2019) of the available meteorological data from Laimburg meteorological station. Simulations were then extended for another 6 years from 2010 to 2015 for model parameterization and performance evaluation purposes. 


\subsubsection{Parameterization}

Key parameters of the new sub-model as well as other PFT-specific parameters were parameterized using the first 3 years of simulations between 2010 and 2012. The length of phenological stages and associated parameters were determined based on field observations of bud burst, full bloom, and harvest as well as non-cultivar specific apple phenology descriptions that were found in the literature (Appendix C). C allocation coefficients were calculated based on the monthly measurements in 2010, by dividing the biomass growth of the individual plant organs by the total biomass increment. Subsequently, model parameters associated with the $\mathrm{CN}$ allocation subroutine (Eq. (2) - (7)) were calibrated manually to match the coefficients obtained from the observations and the overall biomass partitioning on a yearly basis. Parameter values for $\mathrm{C}: \mathrm{N}$ ratios of all plant organs and maximum LAI were based on field observations in 2010 and 2010-2012, respectively. The specific leaf area index was calculated by dividing monthly measurements of LAI by leaf biomass and taking the average of the obtained values. Plant morphological parameters such as maximum tree height, stocking density, or rooting depth were adjusted based on site-specific information. The CLM5 root distribution parameter, which sets the root ratios at different depths, was calibrated by least squares regression of the measured root ratios at $0-20 \mathrm{~cm}, 20-40 \mathrm{~cm}$, and $40-60 \mathrm{~cm}$ depths and the calculated ratios. Optical parameters for leaf transmittance and reflectance in the visible and near-IR were set to average values reported for apple by Bastías and Corelli-Grappadelli (2012). Stem reflectance and transmittance were assumed to be similar to other woody species and therefore set to the values used for BDT in CLM5, similar to the assumptions made by Fan et al. (2015) for the palm tree development in CLM4.5. The ratio of momentum roughness length to canopy top height was set to the average value of the ranges reported for apple and citrus orchards (Tanny and Cohen, 2003; La Fuente-Sáiz et al., 2017). No specific values could be found for the ratio of displacement to top of canopy height, the leaf orientation index, or the intercept to calculate the top of canopy maintenance respiration base rate. These values were assumed to be comparable to other deciduous trees and thus set to the values used for BDT in CLM5. Parameters related to C reserve dynamics (e.g., $f c u r)$ and photosynthesis (e.g., the slope of the relationship between leaf $\mathrm{N}$ per unit area and the maximum rate of carboxylation at $25{ }^{\circ} \mathrm{C}$ ) were adjusted to match observed LAI and productivity data. All parameters with their values and references to the literature are summarized in Table $\mathrm{C} 1$ of the Appendix.

\subsubsection{Sensitivity Analysis}

A simple one-by-one sensitivity analysis was performed to further tune model parameters and assess the influence of newly added parameters on the simulations. As a complete sensitivity analysis of all PFT-related parameters would have exceeded the scope of this study, the analysis focused on key parameters of the new phenology and CN allocation subroutines. Other potentially influential parameters were selected based on previously performed sensitivity analyses by Göhler et al. (2013) for

305 CLM3.5, and by Cheng et al. (2020) and Dagon et al. (2020) for CLM5 taking into account differences between previous and current model versions. Parameters selected for the analysis were perturbed by varying a parameter by $\pm 30 \%, \pm 20 \%$, and \pm 10 $\%$ while keeping the others fixed to the value of the control simulation (after initial parameterization). The goal here was not 
to perform an in-depth analysis covering the full range of possible parameter values, but rather to provide a first indication of influential parameters in the new sub-model similar to the approach of Fan et al. (2015). As a measure of sensitivity, the parameter effect (PE) was calculated using the average of 3 years of simulations between 2013 and 2015 of the control and the perturbed simulations for selected output variables and the following formula adjusted from Luo et al. (2020):

$$
\begin{aligned}
& \Delta X_{i, j}=\sum_{k=1}^{n} \frac{\left|\overline{X_{l, j, k}}-\overline{X_{l, \text { control }}}\right|}{\mid \overline{X_{l, \text { control }} \mid},} \\
& P E_{i, j}=\frac{\Delta X_{i, j}}{\max \left[\left(\Delta X_{i, j}\right)_{1 \leq i \leq n ; 1 \leq j \leq m}\right]},
\end{aligned}
$$

where $k$ is the parameter perturbation factor, $i$ is the $\mathrm{i}^{\text {th }}$ variable across $n=6$ selected output variables including: GPP, NEE, $\mathrm{R}_{\mathrm{a}}, \mathrm{LE}$, maximum LAI, and yield, $j$ is the $\mathrm{j}^{\text {th }}$ parameter across $m$ selected parameters. $P E_{i, j}$ is a number between 0 and 1 that represents the sensitivity of an output variable $i$ to the parameter $j$, with 1 meaning high and 0 meaning low sensitivity. The parameters selected for sensitivity analysis are indicated in Table $\mathrm{C} 1$ of the Appendix.

\subsubsection{Model performance evaluation}

Modelling results are compared to observed biomass, yield, and LAI data as well as ecosystem fluxes retrieved from the EC measurements. Statistical indices for model performance evaluation include the Pearson's coefficient of correlation (r), the root mean square error (RMSE) and the percent bias error (\%bias):

$$
\begin{aligned}
& r=\frac{\left(\frac{1}{n} \sum_{i=1}^{n}\left(X_{i}^{o}-\mu^{o}\right) *\left(X_{i}-\mu\right)\right)}{\sigma * \sigma^{o}}, \\
& R M S E=\sqrt{\frac{1}{n} \sum_{i=1}^{n}\left(X_{i}-X_{i}^{o}\right)^{2}}, \\
& \% \text { bias }=\frac{\sum_{i=1}^{n}\left(X_{i}-X_{i}^{o}\right)}{\sum_{i=1}^{n}\left(X_{i}^{o}\right)},
\end{aligned}
$$

where $i$ is the time step, $n$ is the total number of time steps, and $X_{i}$ and $X_{i}^{o}$ are simulated and observed values at each time step respectively, $\mu$ and $\mu^{o}$ are simulated and observed mean values, respectively, and $\sigma$ and $\sigma^{o}$ are simulated and observed standard deviations. 
https://doi.org/10.5194/gmd-2022-41

Preprint. Discussion started: 16 February 2022

(c) Author(s) 2022. CC BY 4.0 License.

(c) (i)

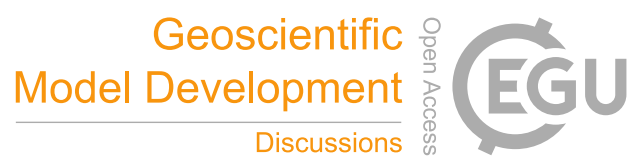

\section{Results and discussion}

\subsection{Sensitivity analysis}

A total of 34 parameters were initially considered for the sensitivity analysis of which the 13 most influential parameters (PE $>0.1$ for at least one of the selected output variables) are shown in Fig. 3. GPP, NEE, $R_{a}$, and yield have similar sensitivity patterns and are most sensitive to the leaf $\mathrm{C}: \mathrm{N}$ ratio (leafcn) and the relationship between leaf $\mathrm{N}$ and the maximum rate of carboxylation at $25^{\circ} \mathrm{C}\left(s_{-} \_c a d\right)$. Together with the specific leaf area (slatop) and other constants, they control the maximum photosynthetic capacity in the photosynthesis calculation and thus largely influence total C assimilation. As expected, LAI is most influenced by parameters that control the $\mathrm{CN}$ allocation to leaves such as the initial leaf allocation coefficient (fleafi), the GDDs needed to reach canopy maturity (lfmat), the maximum LAI (laimx), photosynthetic parameters, and, to a smaller extent, the fraction of $\mathrm{C}$ allocated to the leaf storage pool to refill $\mathrm{C}$ reserves (aleafstor). The first three parameters influence leaf biomass and thus show a considerable effect on GPP, NEE, $\mathrm{R}_{\mathrm{a}}$, and yield. The same output variables are affected in a similar fashion by the GDDs needed until fruit harvest (hybgdd) that control the amount of $\mathrm{C}$ allocated to fruits. LE is influenced largely by the parameter controlling stomatal conductance (medlynslope), and the photosynthetic parameters (leafcn, s_vcad). Overall, photosynthetic parameters play a key role in determining the magnitude of the studied output variables with an average

340 PE value close to 0.7 across all six variables. Phenological parameters (top seven parameters in Fig. 3 ) are generally less influential for the same output variables with average PE values up to 0.43 . These findings are largely consistent with earlier studies of parameter sensitivity (Göhler et al., 2013; Cheng et al., 2020; Dagon et al., 2020; Luo et al., 2020). In contrast to Luo et al. (2020) we did not find a strong effect of the root distribution parameter (rootprof_beta) on LE, which can be attributed to the low water stress due to the irrigation management of the studied orchard.

345 While the one-at-a-time sensitivity analysis provides some insight into model sensitivity, the ranking of influential parameters is strongly influenced by the choice of parameters and output variables, the parameter perturbation strategy (i.e. percent change, linear sampling), and the index chosen as the sensitivity measure. Parameter tuning based on this analysis is further complicated since this approach does not consider parameter covariation that is particularly strong for plant parameters that influence photosynthesis (Göhler et al., 2013). Selecting parameter values based on the individual best simulation hence does not necessarily yield the best overall result (Luo et al., 2020). We therefore decided to first adjust $s_{-} v c a d$ to best match the observed average GPP. In the following, we further adjusted fleafi, hybgdd and medlynslope to improve the simulated biomass components as well as the LE flux, respectively. 


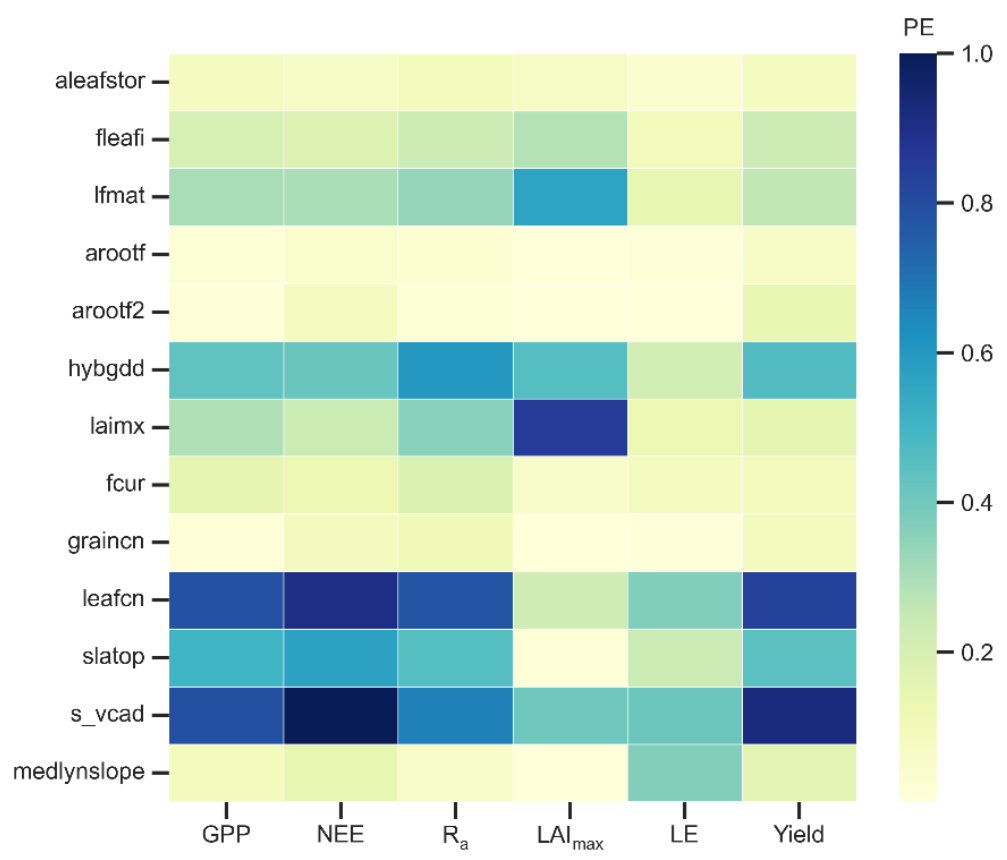

Figure 3: Parameter effect (PE) as a measure of sensitivity of selected output variables to the most influential model parameters. Output variables include gross primary production (GPP), net ecosystem exchange (NEE), autotrophic respiration (Ra), maximum leaf area index (LAI $I_{\text {max }}$, latent heat flux (LE) and yield. Parameters are: Post-harvest leaf allocation coefficient to storage (aleafstor), initial leaf allocation coefficient (fleafi), GDD to canopy maturity (lfmat), root allocation coefficients at the start of fruit development (arootf) and until harvest (arootf2), GDD needed until harvest (hybgdd), maximum LAI (laimx), fraction of allocation that goes to currently displayed growth (fcur), $\mathrm{C}: \mathrm{N}$ ratios of fruits (graincn) and leaves (leafcn), specific leaf area at top of canopy (slatop), slope of the relationship between leaf $\mathrm{N}$ per unit area and the maximum rate of carboxylation at $25{ }^{\circ} \mathrm{C}\left(\mathrm{s} \_\right.$vcad), and the medlyn slope of the conductance-photosynthesis relationship (medlynslope). For more details on the parameters, see Appendix C.

\subsection{Modelling results}

In the following, we present the modelling results according to the initial parameterization and the updated parameters values from the sensitivity analysis. Daily simulations or yearly sums are compared to observed biomass, yield, and LAI data as well as ecosystem fluxes retrieved from the EC measurements aggregated to daily mean values.

\subsubsection{Biomass growth and yield}

The patterns in seasonal biomass allocation simulated by CLM-FruitTree show good agreement with the monthly observations from 2010 (Fig. 4a). The beginning and end of the growing season are well captured. After bud break in the beginning of March, biomass is primarily allocated to the vegetative organs of leaves, fine roots, and woody organs, and growth is supported by $\mathrm{C}$ and $\mathrm{N}$ reserves until the start of fruit growth in early May. In the following months, fruit biomass grows rapidly until harvest takes place in mid-October, following the typical sigmoidal growth curve that is well captured by the new phenology 
and $\mathrm{CN}$ allocation. Leaf biomass peaks in early July and remains constant thereafter, with leaf offset starting later October when temperatures drop below $4{ }^{\circ} \mathrm{C}$. Pruning is performed when the tree enters dormancy by removing $85 \%$ of the stem biomass assimilated over the season according to the observed pruning amounts in the studied apple orchard (Zanotelli et al., 2013; Zanotelli et al., 2015). From 2010 to 2012, the modelled percentage of biomass allocation to plant organs was generally in agreement with the observations (Zanotelli et al., 2015) with differences ranging between 1 and $5 \%$ for fruits, leaves, aboveground wood, and roots (Fig. 4b). Penzel et al. (2020) stated that different studies reported biomass allocation to fruits ranging from 50 to $85 \%$ depending on apple cultivar suggesting considerable variability in allocation coefficients. This emphasizes the benefit of a cultivar specific calibration in order to obtain realistic modelling results. On the other hand, it suggests that a more general parameterization, that reflects an average apple tree, may be necessary to apply CLM-FruitTree at larger scales and across multiple cultivars.

(a) Biomass growth (2010)

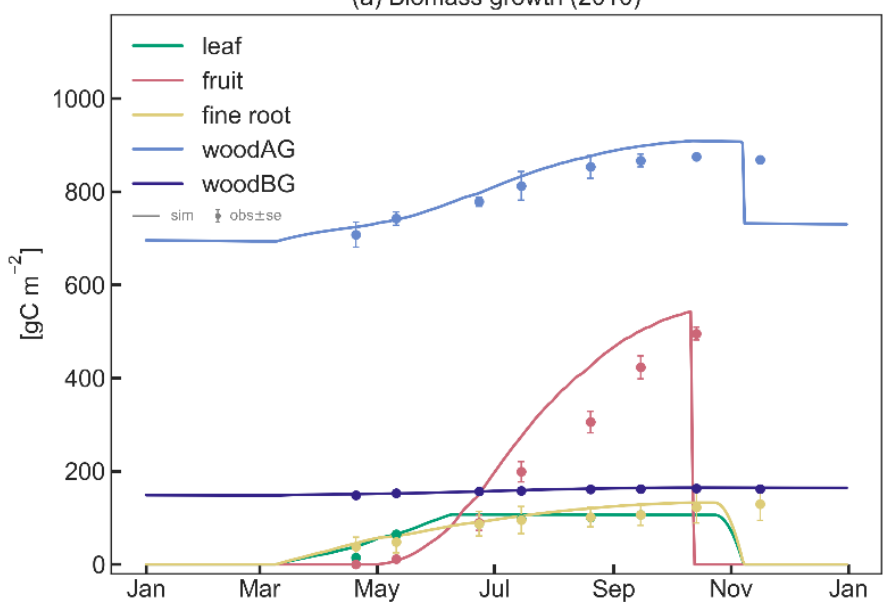

(b) Biomass partitioning (2010-2012)

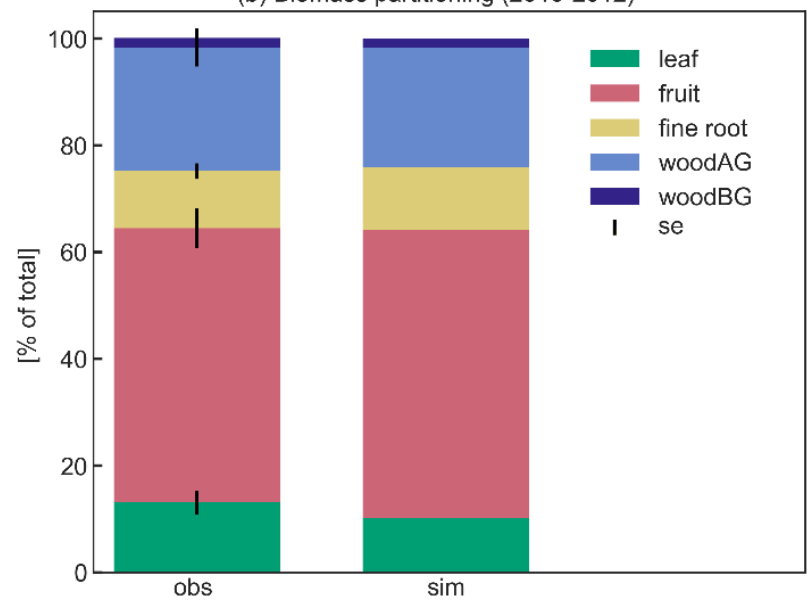

Figure 4: (a) Observed and simulated growth of leaves, fruits, fine roots, aboveground (live and dead stem), and belowground biomass (live and dead coarse roots) during 2010. (b) Observed and simulated biomass components between 2010 and 2012 as percentage of total biomass.

The timing for initial leaf development in spring and leaf offset in late autumn are sufficiently well captured by the implemented bud burst prediction algorithm and the simple temperature threshold for leaf abscission respectively (Fig. 5). Observed maximum LAI varied between 2.8 and $3.3 \mathrm{~m}^{2} \mathrm{~m}^{-2}$ and occurred during the first half of July. The simulations reached similar values in 2010 and 2012 matching the observations, while the lower simulated LAI in 2011 underestimated measurements due to a smaller $\mathrm{C}$ transfer from storage and lower solar radiation early in the growing season. Such discrepancy could be further related to a light pruning performed in the previous winter (Zanotelli et al., 2013). Such management is performed to counteract the well-known alternate bearing behaviour of the Fuji apple, which causes a substantial drop in yield following a high yielding year (Belleggia et al., 2009; Atay et al., 2013; Pasa et al., 2021). In consequence to the light pruning, a larger amount of vegetative and flower buds remained on the tree leading to a higher yield and, possibly explaining the larger discrepancy between relatively high observed LAI and relatively low simulated values. Measured LAI showed a slow decline 
soon after maximum LAI was reached, while simulated values in contrast are assumed to remain constant until the leaf-offset period is initiated. The observed early decline may be an artefact of the sampling strategy used to determine LAI that extrapolated individual leaf area measurements to the whole tree, assuming a constant leaf distribution within the tree (Zanotelli et al., 2013). Another reason could be a limited leaf fall occurring during the summer at the expense of the inner shadowed leaves, as noted during field sampling. Other studies suggest that the LAI of fruit trees generally stays constant until a rapid decline with the onset of senescence (Lakso et al., 1999; Pallas et al., 2016), supporting the simulated LAI dynamic.

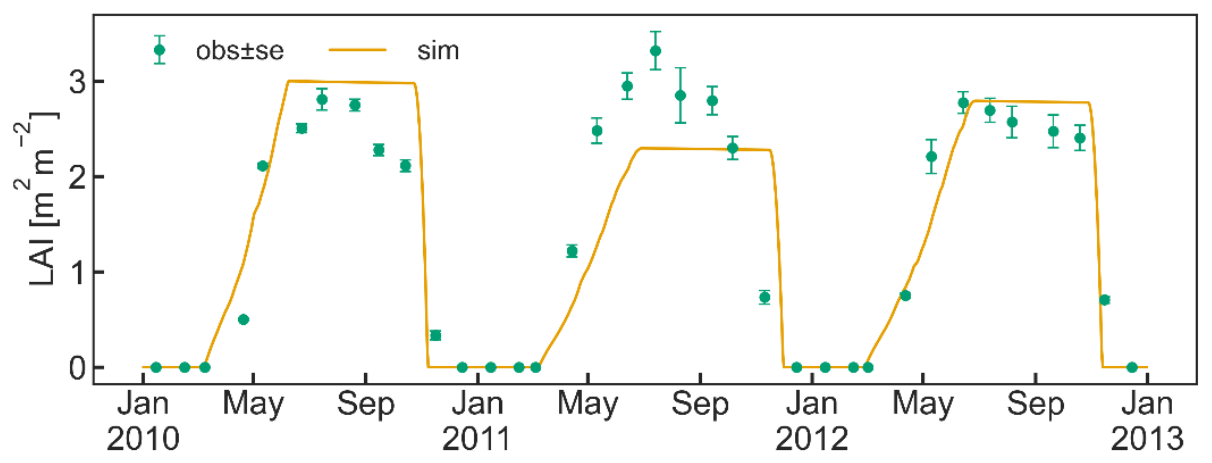

Figure 5: Observed ( \pm standard error) and simulated leaf area index (LAI) between 2010 and 2012.

Simulated yield averaged at $70 \mathrm{t} \mathrm{ha}^{-1}$ between 2010 and 2015 and was within $2.3 \%$ of the observed average yield. While simulated yield varied between 61 and $76 \mathrm{t} \mathrm{ha}^{-1}$, the observations showed a greater inter-annual variability, as exemplified in the case of the year 2012 (low yield of $51 \mathrm{t} \mathrm{ha}^{-1}$ ) and 2015 (high yield of $101 \mathrm{t} \mathrm{ha}^{-1}$ ) (Fig. 6). Low inter-annual variability of yield has also been observed in previous crop simulations with CLM5 for winter wheat (Boas et al., 2021) suggesting that additional drivers of yield variability such as specific management practices are not represented with sufficient detail in CLM5. In the case of apple trees, yield is tightly linked to the number of flowers and early fruit growth, which in turn depend on a complex interaction of the environmental conditions during winter dormancy and the start of the new growing season (Chmielewski et al., 2012; Corelli-Grappadelli and Lakso, 2002). Additionally, C reserves accumulated in the previous year (Greer et al., 2002) and crop load management play an important role in determining the final harvest (Penzel et al., 2020). The latter includes pruning or fruit thinning to ensure optimal fruit growth and prevent alternate bearing. The low observed yield in 2012 may be a result of such behaviour. Storage growth is considered in CLM-FruitTree and exhibited an impact on the final yield of the following season as shown by the sensitivity analysis of the aleafstor and fcur parameters (Fig. 3). However, its effect on fruit growth in CLM-FruitTree is indirect since it supports leaf development in the early growth stage but does not directly contribute to fruit growth. Identifying the driving forces of reserve deposition and mobilization, and their quantification remains an unsolved issue and there is yet no consistent formulation of this process in tree modelling (Le Roux et al., 2001; Allen et al., 2005). Predicting final yield in fruit orchards is further complicated by the fact that harvest is usually based on certain fruit quality traits such as firmness, or soluble solids and can occur successively as fruits may not mature at 
the same time (Corelli-Grappadelli and Lakso, 2002; Musacchi and Serra, 2018). Within this context, the proposed simplifications of the $\mathrm{C}$ reserve dynamics and fruit harvest are likely reasons for the difference in observed and simulated yields while the missing representation of specific crop load management practices regarding the Fuji apple contributed to the low variability in simulated yields. Considering the many specific challenges in modelling this apple cultivar, we believe that the yield predictions are satisfactory enough in the context of the sub-model development.

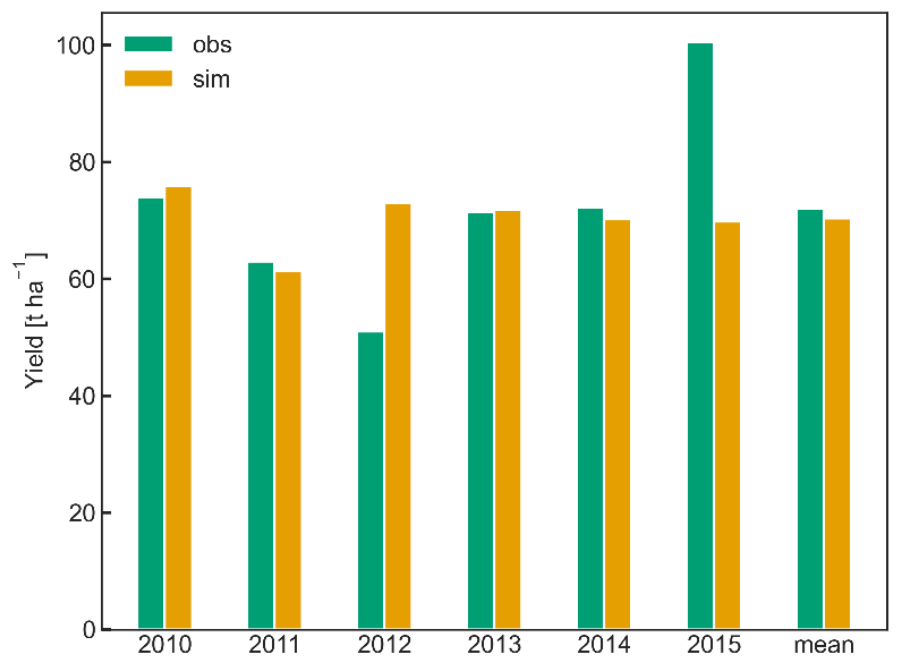

Figure 6: Annual yields from 2010 to 2015 and their mean in tons of fresh weight per hectare. For the conversion of simulated fruit biomass in gram carbon per square metre to tons per hectare, fruit $\mathrm{C}$ content was assumed $42 \%$ of total dry weight, harvest efficiency was assumed $95 \%$, and fruit water content $83 \%$ according to Zanotelli et al. (2013).

\subsubsection{Ecosystem fluxes and soil moisture variation}

\section{Carbon fluxes}

As shown in Fig. 7, CLM-FruitTree was able to capture the overall patterns of GPP, NEE, and Reco, particularly during the transition between dormancy periods and growing seasons (April to November). Simulated C fluxes are highly correlated with observations ( $\mathrm{r} \geq 0.84$ ) while the RMSE ranges between 1.12 and $1.53 \mathrm{gC} \mathrm{m}^{-2} \mathrm{~d}^{-1}$. Observed and simulated peak $\mathrm{C}$ fixation occurred mid-July (Fig. 7a), corresponding to the maximum (negative) NEE (Fig. 7c) and maximum LAI (Fig. 5). Simulated NEE becomes negative (net carbon sink) around April and returns positive (net carbon source) around November in agreement with the observed dynamic (Fig. 7c). Observed yearly sums of GPP (NEE) were $1.60(-0.49), 1.43(-0.48)$, and $1.65(-0.76)$ $\mathrm{kgC} \mathrm{m}^{-2} \mathrm{yr}^{-1}$ for 2013, 2014, and 2015, respectively. Simulated yearly sums of GPP (NEE) were 1.58 (-0.53), 1.56 (-0.51), and $4401.53(-0.57) \mathrm{kgC} \mathrm{m}^{-2} \mathrm{yr}^{-1}$ for the same years showing a negligible positive bias of on average $0.17 \%$ for GPP (Fig. $7 \mathrm{~b}$ ) and a small underestimation (less negative) of on average $3.8 \%$ for NEE (Fig. 7d). Simulated and observed Reco (Fig. 7e) generally increased until July, because of the increase in air temperature and respiratory costs of the developing canopy, and declined thereafter as air temperature started to drop. Simulations of $\mathrm{R}_{\text {eco }}$ tend to slightly underestimate observations between April and late August and to overestimate observations during winter, although discrepancies are relatively small. Observed yearly sums 
https://doi.org/10.5194/gmd-2022-41

Preprint. Discussion started: 16 February 2022

(c) Author(s) 2022. CC BY 4.0 License.

(c) (i)

445 of $\mathrm{R}_{\text {eco }}$ were 1.13 (2013), 0.98 (2014), and 0.94 (2015) $\mathrm{kgC} \mathrm{m}^{-2} \mathrm{yr}^{-1}$ while simulated values were $1.08,1.08$, and $0.99 \mathrm{kgC} \mathrm{m}^{-2}$ $\mathrm{yr}^{-1}$, respectively. CLM-FruitTree overestimated yearly $\mathrm{R}_{\mathrm{eco}}$ by on average $3.3 \%$ explaining most of the difference in observed and simulated NEE in 2013, while differences in 2014 and 2015 are owed to a combination of small biases in both GPP and $\mathrm{R}_{\text {eco. }}$. Measured $\mathrm{R}_{\text {eco }}$ showed irregular fluctuations in the early part of the growing season 2013, and mid- to late-season 2014 and 2015 that are not reproduced well by the model. These fluctuations mostly correspond to the observed temperature dynamics (not shown) as a result of the applied gap filling that is based on an air (or soil) temperature- $\mathrm{R}_{\text {eco }}$ relationship (Reichstein et al., 2005). Such discrepancies between observed and simulated dynamics could be further explained by the occurrence of field management practices such as mowing of the grassed alleys or soil tillage under the tree rows, which are currently not represented in CLM-FruitTree. Such practices could have led to a temporary rise in soil respiration $\left(\mathrm{R}_{\mathrm{s}}\right)$ due to increased heterotrophic respiration $\left(\mathrm{R}_{\mathrm{h}}\right)$ as discussed in Zanotelli et al. (2013). Indeed soil tillage experiments performed in an apple orchard located in a Loess plateau in Shaanxi Province in China were found to increase $\mathrm{R}_{\mathrm{s}} 14-57 \%$ depending on the tillage method (Hou et al., 2021).

Zanotelli et al. (2013) measured a total $\mathrm{R}_{\mathrm{s}}$ of $801 \pm 95 \mathrm{gC} \mathrm{m}^{-2}$ in 2010 contributing around $90 \%$ to $\mathrm{R}_{\mathrm{eco}}$, based on soil chamber measurements within the orchard (total soil respiration). The comparison with parallel measurements in a trenched plot produced a high ratio $R_{h} / R_{s}$ of 0.77 for the apple orchard. In contrast, simulated $R_{\text {eco }}$ for the same year was dominated by autotrophic respiration $\left(\mathrm{R}_{\mathrm{a}}\right.$ ) due to high $\mathrm{C}$ costs for maintenance, mainly of leaf biomass (not shown). Total simulated $\mathrm{R}_{\mathrm{s}}$ contributed merely $45 \%\left(510 \mathrm{gC} \mathrm{m}^{-2}\right)$ to $\mathrm{R}_{\text {eco }}$ with a ratio $\mathrm{R}_{\mathrm{h}} / \mathrm{R}_{\mathrm{s}}$ of 0.87 . Other studies found that $\mathrm{R}_{\mathrm{s}}$ contributed $56-67 \%$ to $\mathrm{R}_{\text {eco }}$ in irrigated citrus orchards of different ages (Martin-Gorriz et al., 2020) and $>60 \%$ in forest ecosystems where the magnitude of ecosystem fluxes is generally comparable to orchards (Lasslop et al., 2012; Zanotelli et al., 2013).

In addition to the missing representation of certain management practices, CLM-FruitTree currently does not account for an

465 active ground cover in the orchard which has shown to enhance $\mathrm{R}_{\mathrm{s}}$ in an Italian olive orchard through increased fine root and microbial biomass (Turrini et al., 2017). Furthermore, the simplified representation of microbial activity in CLM5, through fixed respiration fractions for litter and soil organic matter pools, may limit the ability of CLM-FruitTree to accurately represent soil respiration processes. Not accounting for mycorrhizal respiration may fail to adequately represent $\mathrm{R}_{\text {eco }}$ of the orchard, as measurements suggested a substantial contribution of $11 \pm 6 \%$ to total $R_{s}$ in an apple orchard (Tomè et al., 2016). Lastly, biases

470 in simulated soil temperature or soil organic matter content could partially contribute to explain the above-discussed differences.

$\mathrm{R}_{\mathrm{a}}$ in CLM5 is the sum of maintenance and growth respiration for the different plant organs as well as the C cost associated with $\mathrm{N}$ uptake from the soil, whereby maintenance respiration comprises the main part of $\mathrm{R}_{\mathrm{a}}$ (78\% on average in this study). CLM5 calculates maintenance respiration based on tissue $\mathrm{N}$ content, temperature, and a constant base maintenance rate. This

475 however, does not account for a lower or varying maintenance cost observed in mature apple orchard canopies compared to annual crops (Bepete and Lakso, 1996; Lakso et al., 1999). It therefore seems likely that the cost for leaf maintenance for the orchard is unrealistically high in CLM-FruitTree, accounting for on average $45 \%$ of $\mathrm{R}_{\mathrm{a}}$ or $28 \%$ of $\mathrm{R}_{\text {eco. }}$. In comparison, in citrus orchards, with an evergreen canopy, leaf respiration was found to contribute 18-20\% to annual $\mathrm{R}_{\mathrm{eco}}$ (Martin-Gorriz et 
https://doi.org/10.5194/gmd-2022-41

Preprint. Discussion started: 16 February 2022

(c) Author(s) 2022. CC BY 4.0 License.

(c) (1)

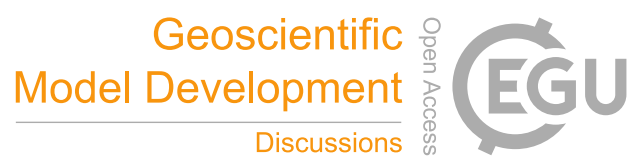

al., 2020). This could also explain the lower simulated carbon use efficiency (NPP/GPP) of 0.59 compared to 0.71 found by

(a) Daily GPP

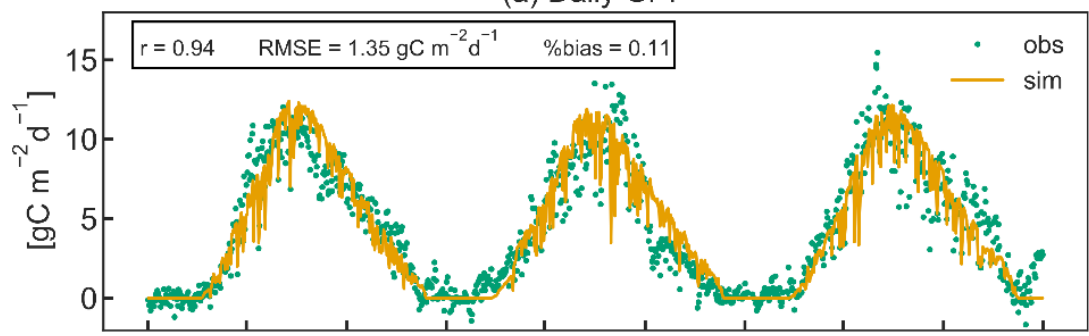

(c) Daily NEE

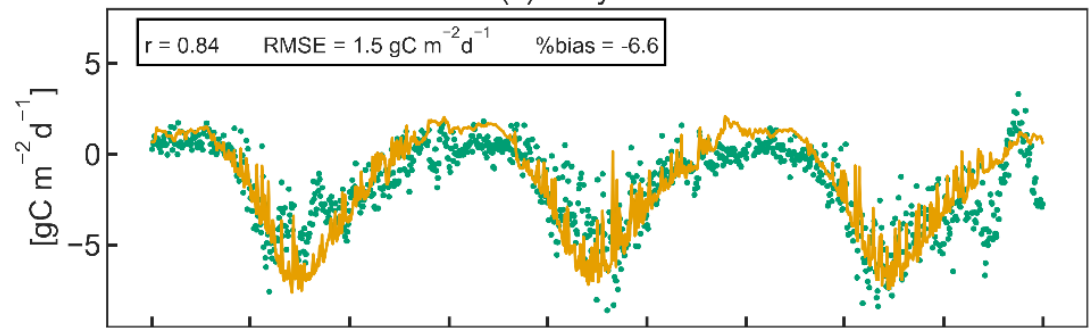

(e) Daily $R_{\text {eco }}$

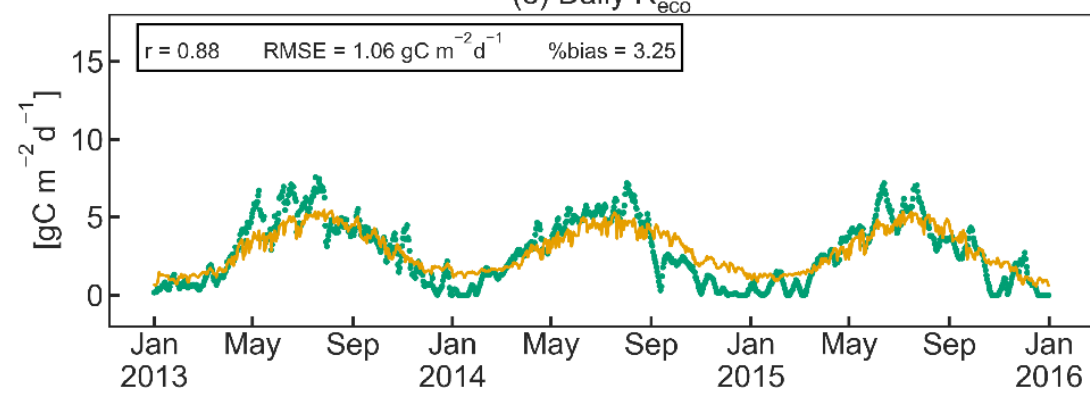

(b) Cumulative GPP

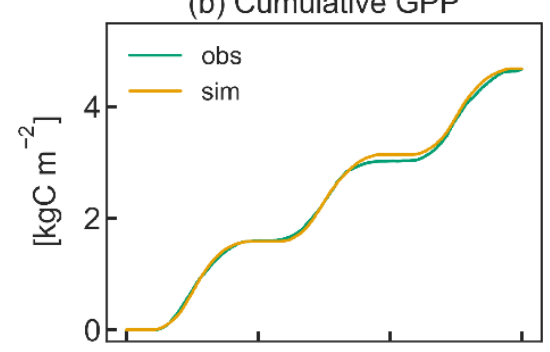

(d) Cumulative NEE

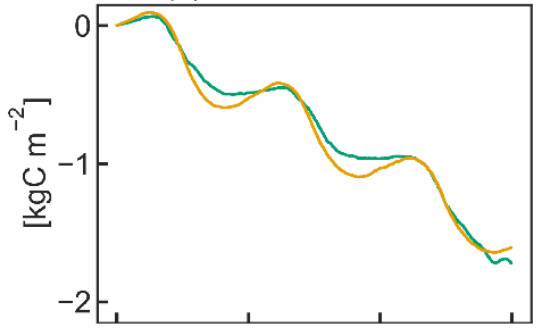

(f) Cumulative $R_{\text {eco }}$

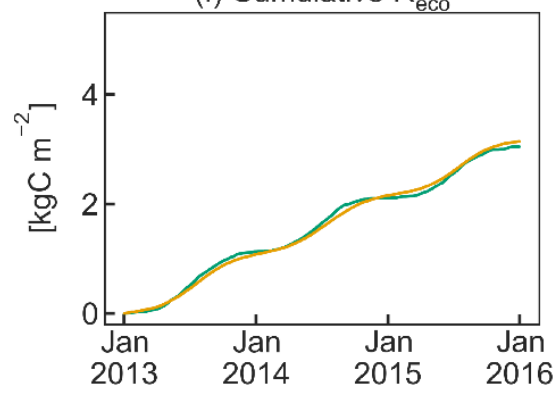

Figure 7: Daily instantaneous (a, c, e) and cumulative (b, d, f) observed and simulated fluxes of gross primary productivity (GPP), net ecosystem exchange (NEE), and ecosystem respiration $\left(\mathbf{R}_{\text {eco }}\right)$ for the studied apple orchard between 2013 and 2015 . Pearson's coefficient of correlation (r), the root mean square error (RMSE) and the percent bias (\% bias) are displayed as statistical indices.

\section{Energy and water fluxes}

The simulated seasonal course of the energy balance components $R_{n}, G, L E$ and $H$ agrees well with observed dynamics in the orchard (Fig. 8). CLM-FruitTree shows a high performance in reproducing $R_{n}$ and LE with $r \geq 0.97$ and RMSE of 15.98 and $17.85 \mathrm{~W} \mathrm{~m}^{-2}$, respectively (Fig. 8a and c). Due to the lack of $\mathrm{LW}_{\text {in }}$ measurements, the CLM5-internal $\mathrm{LW}_{\text {in }}$ calculation based on a clear-sky parameterization after Idso (1981) was used initially. This resulted in a significant underestimation of $5 \%$ (511 MJ) for $L W_{i n}$ and $18 \%$ (471 MJ) for $R_{n}$ compared to the observations in 2010. The $R_{n}$ bias could be reduced by $14 \%$ for the observed time series when $\mathrm{LW}_{\text {in }}$ was calculated by considering cloud cover as described in Appendix $\mathrm{B}$. This stresses the necessity to account for cloud cover, ideally combined with locally calibrated parameters, for an accurate calculation of $\mathrm{LW}_{\text {in. }}$. The remaining small negative bias of $4.48 \%$ in $R_{n}$ is due to negative simulated $R_{n}$ during the winter months (Fig. 8b), which 
https://doi.org/10.5194/gmd-2022-41

Preprint. Discussion started: 16 February 2022

(c) Author(s) 2022. CC BY 4.0 License.

\section{(c) (i)}

may be a result of the higher reflectance of solar radiation from bare soil compared to a grass surface (Bryś et al., 2019). The model assumes a bare soil (except for stem area) during the dormancy period, as the grass-covered alleys in the orchard are not considered explicitly.

The simulated LE (Fig. 8c) shows similar dynamics and variability as the observations following the increase and decrease of GPP (Fig. 7a) and LAI (Fig. 5). Similarly to LE, modelled ET shows a high correlation coefficient of 0.97 and small RMSE of $0.62 \mathrm{~mm} \mathrm{~d}^{-1}$ (Fig. 8i). Simulated ET exceeds observed ET by $1.1 \mathrm{~mm} \mathrm{~d}^{-1}$ on average during its peak in July but the overall bias is almost negligible (Fig. 8j). Total observed ET is 901 (2013), 858 (2014), and 883 (2015) mm while corresponding simulated values are 916, 877, and $925 \mathrm{~mm}$, respectively. When examining the order of magnitudes of the ET components, canopy transpiration takes up around $85 \%$ of ET, followed by soil evaporation and canopy evaporation (data not shown). Typically, apple orchard ET represents a combined flux from the apple trees and the grassed alley system, which is not explicitly represented in CLM-FruitTree since CLM5 does currently not consider inter-row grass coverage or intercropping. Ntshidi et al. (2021) found that the contribution of understory transpiration is high in young, non-bearing apple orchards, but contributes less than $10 \%$ to whole orchard ET in mature orchards with high canopy cover, which may explain the good model performance despite not considering the grass cover.

Simulated $\mathrm{H}$ and $\mathrm{G}$ are less consistent with the observations with $\mathrm{r}$ values of 0.54 and 0.64 , respectively, and large \%bias (Fig. $8 \mathrm{e}$ and $8 \mathrm{~g}$ ), which is partially due to the much smaller magnitudes of the two fluxes compared to $R_{n}$ and $L E$. A possible reason for the lower amplitude of observed G (Fig. 8h) compared to simulated values may be the dampening effect of the grass cover providing additional shading during summer and insolation during winter (Bryś et al., 2019; Oorthuis et al., 2021). Observed $\mathrm{H}$ was rather constant throughout the year with slightly higher values at the start and end of the growing season when the canopy was not yet fully developed, or leaves were shedding. CLM-FruitTree simulated a clear rise of $\mathrm{H}$ until April, closely following the observations, but $\mathrm{H}$ thereafter declined steeply in May with negative values in August 2013 and 2015. Negative

$515 \mathrm{H}$ during August corresponds with maximum LE and the main simulated irrigation season (June to September) that added 357 (2013), 281 (2014), and $517 \mathrm{~mm}$ (2015) of water to the orchard (Fig. 9a). In a study conducted with CLM4.5, intense irrigation was found to strongly influence the convective heat fluxes by increasing LE and decreasing H (Zeng et al., 2017). Although precise measurements of the irrigation amount in the orchard are not available for the studied period, the average yearly irrigation was estimated around $200 \mathrm{~mm}$ with no irrigation in 2014 due to sufficient rainfall (Montagnani et al., 2018). The difference in irrigation amounts may in part explain why the described phenomena is not observed in the measurements. Indeed negative simulated $\mathrm{H}$ in the summer months occurred as a result of strong evaporative cooling of ground and vegetation temperature through energy absorption by LE following irrigation, that caused simulated LE to exceed simulated $R_{n}$. This behaviour was not observed in the measurements where LE rarely exceeded $R_{n}$ and was mostly owed to an overestimation of simulated LE compared to the measurements. Persisting model weaknesses in the partitioning of the energy balance were pointed out by a recent study examining land surface processes over a tropical rainforest using CLM4.5 and CLM5, and were linked to missing detail in the representation of the canopy and an oversensitivity of vegetation temperature to incoming solar radiation among others (Song et al., 2020). As a result, the authors observed an overestimation of LE and unrealistically high 
https://doi.org/10.5194/gmd-2022-41

Preprint. Discussion started: 16 February 2022

(c) Author(s) 2022. CC BY 4.0 License.

(c) (i)

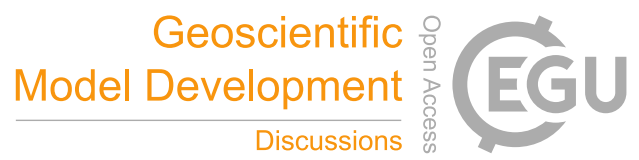

day-to-night changes in $\mathrm{G}$, which was also observed in this study when examining the model output at an hourly time step (results not shown).

530 Energy partitioning in orchards is strongly influenced by the positioning and pruning of branches to optimize tree architecture for higher productivity, planting density, tree height, and LAI distribution (López-Olivari et al., 2016). Consequently, the contribution of $\mathrm{H}$ and LE can significantly differ in patchy compared to closed canopies of annual crops (La Fuente-Sáiz et al., 2017). Next to the aspects discussed above, biases in the simulated energy balance components are hence likely to arise from model limitations to represent such heterogeneous canopies.

\section{Soil moisture variation}

Simulated mean soil moisture (SM) at $5 \mathrm{~cm}$ depth was within $1.6 \%$ vol of the observed value during the three observed growing seasons, despite the higher simulated irrigation amount (Fig. 9b). Simulated daily values show a greater variability than the measured data in response to precipitation and to frequent irrigation (Fig. 9a-b). In contrast, observed SM in the deeper soils (30-60 cm), was 3-11\%vol higher during the growing season compared to simulated values (Fig. 9c-d). Considering the total

540 investigated soil depth, simulations exhibit a larger variability in SM throughout the year, with a general overestimation in winter and underestimation during the growing season (especially in the deeper soils). However, the collected SM data was limited to a single soil profile that may not adequately reflect the average soil moisture of the apple orchard, which should be considered when comparing measurements and simulations. Even though the measurements are incomplete, the constant high observed SM in the deeper soils suggests an ample supply of water due to capillary rise from the shallow ground water table that typically ranges between 1.2 and $1.85 \mathrm{~m}$ in the area (Montagnani et al., 2018). This process replenishes the water removed by ET processes and may explain the reduced need for irrigation compared to the simulations. Despite the shallow simulated ground water table (generally $1.2 \mathrm{~m}$ depth), groundwater could not be used for root water uptake in the simulation as the rooting depth of the orchard was restricted to $0.8 \mathrm{~m}$ according to local measurements and capillary rise is currently not implemented in CLM5. 
https://doi.org/10.5194/gmd-2022-41

Preprint. Discussion started: 16 February 2022

(c) Author(s) 2022. CC BY 4.0 License.

(c) (1)

\section{Geoscientific Model Development \\ Discussions}

(a) Daily $R_{n}$

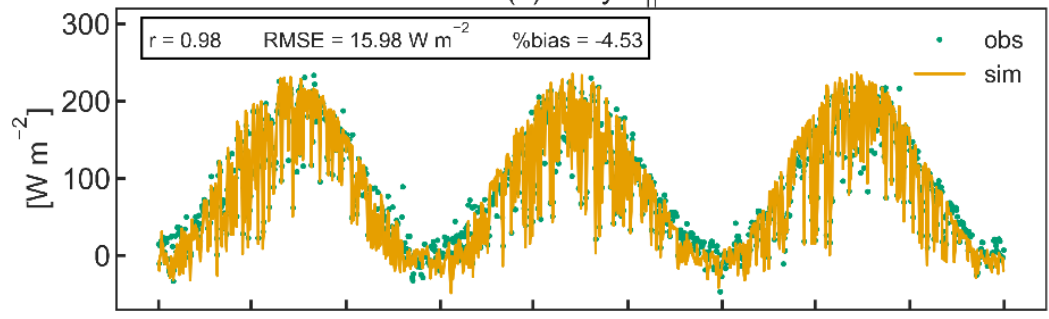

(c) Daily LE

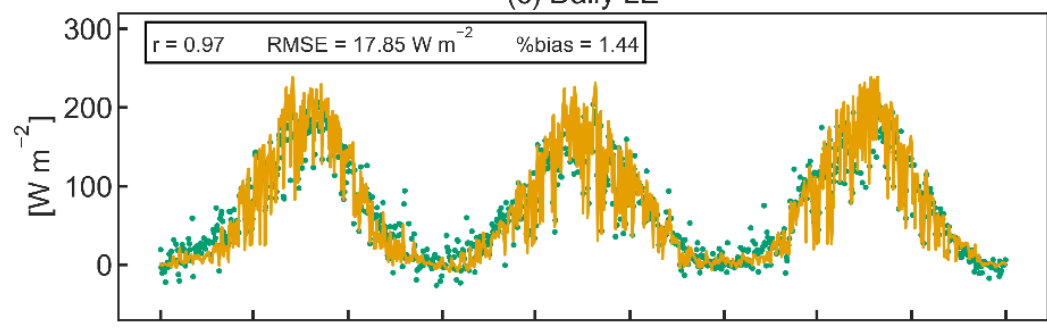

(e) Daily $\mathrm{H}$

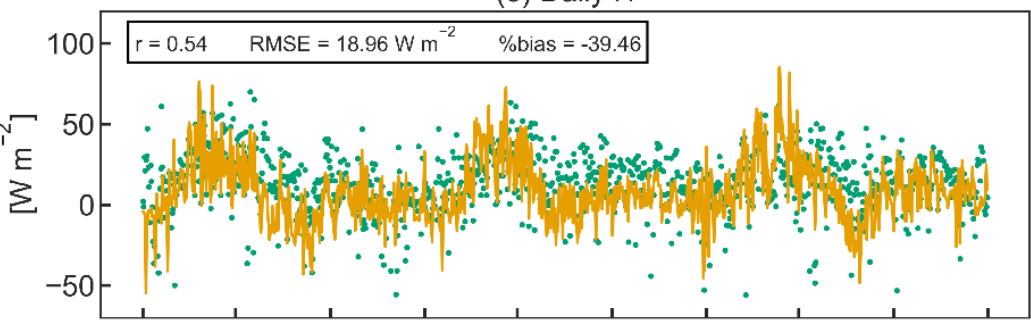

(g) Daily G

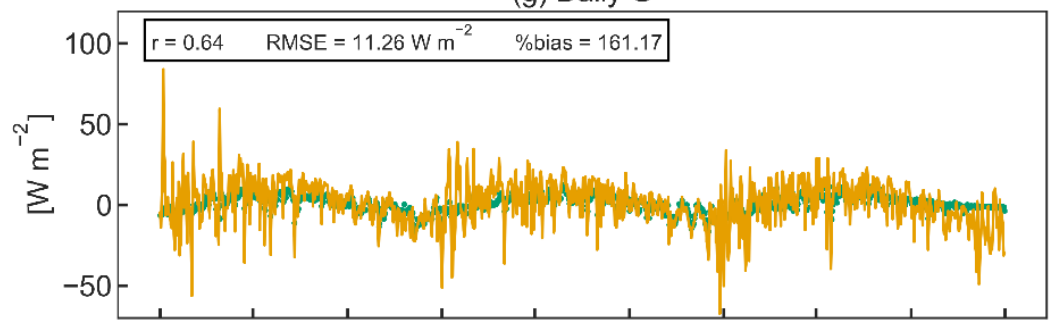

(i) Daily ET

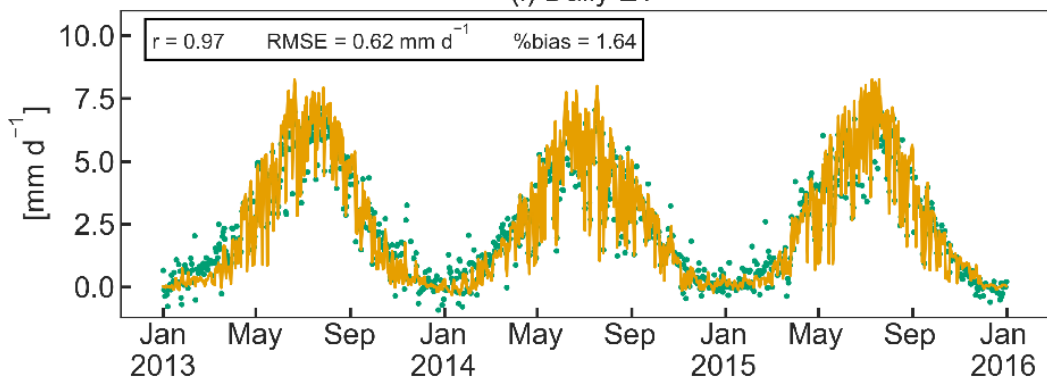

(b) Cumulative $\mathrm{R}_{\mathrm{n}}$

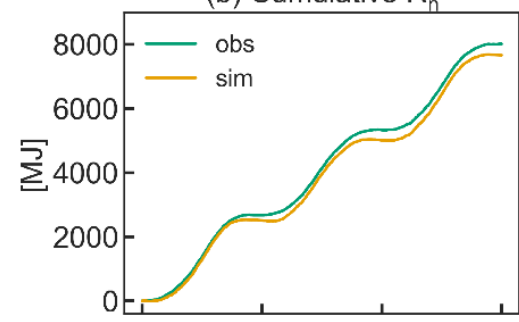

(d) Cumulative LE

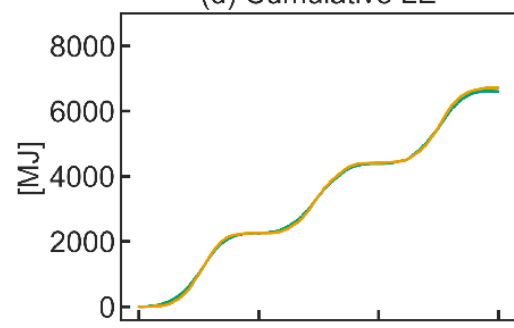

(f) Cumulative $\mathrm{H}$

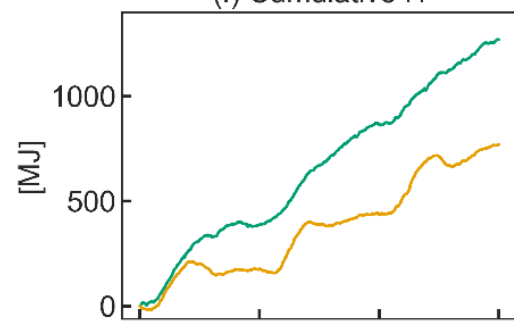

(h) Cumulative G

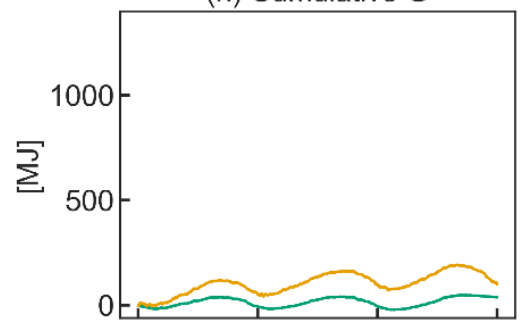

(j) Cumulative ET

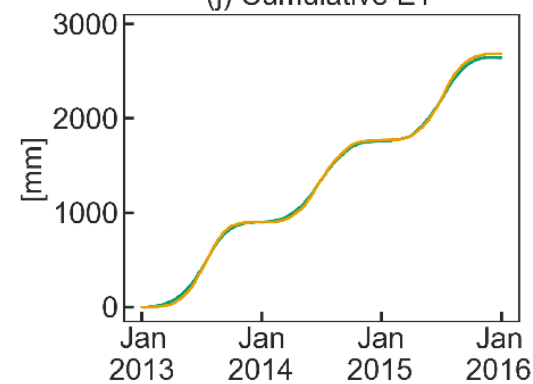

Figure 8: Daily and cumulative observed and simulated fluxes of net radiation $\left(\mathbf{R}_{\mathbf{n}}\right)$, ground heat $(\mathbf{G})$, latent heat $(\mathbf{H})$, sensible heat (LE) and evapotranspiration (ET) for the studied apple orchard between 2013 and 2015. The coefficient of determination (r), the root mean square error (RMSE) and the percent bias (\% bias) are displayed as statistical indices. 
(a) Precipitation//rrigation

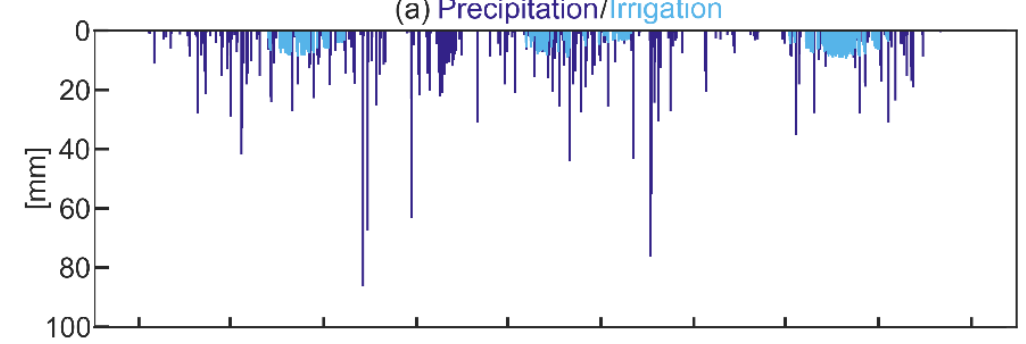

(b) SWC at $0.05 \mathrm{~m}$

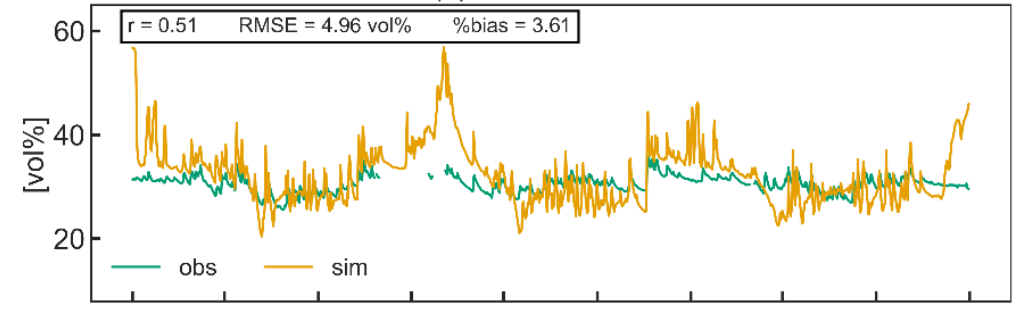

(c) SWC at $0.3 \mathrm{~m}$

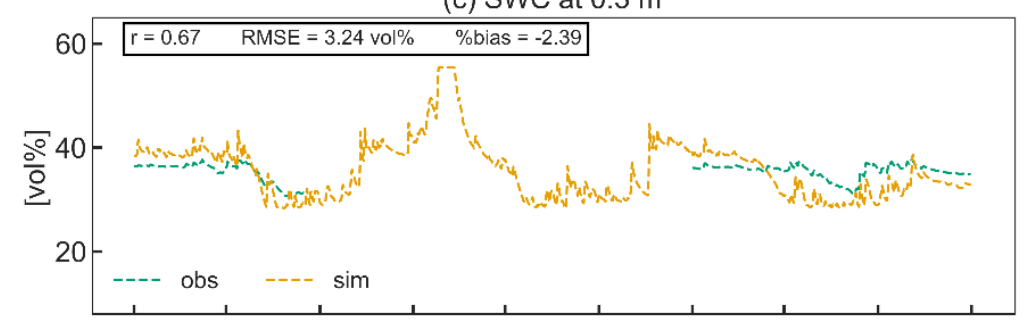

(d) SWC at $0.6 \mathrm{~m}$

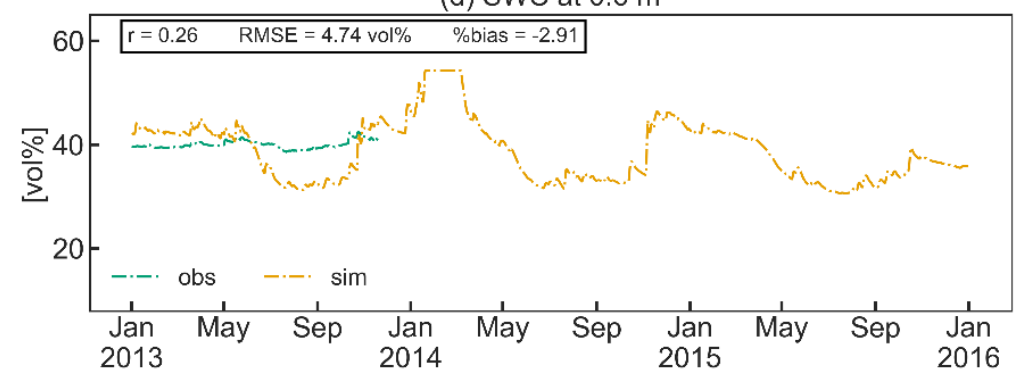

555 Figure 9: Precipitation and simulated irrigation (a), and observed and simulated soil water content (SWC) at 0.05 m (b), 0.3 m (c), and $0.6 \mathrm{~m}(\mathrm{~d})$ depth from $2013-2015$.

\section{Conclusions}

The novel CLM-FruitTree was developed to model perennial deciduous fruit orchards and thus extended the representation of agricultural systems in CLM5. The development included a new phenology subroutine to account for the perennial nature, prolonged growing season, and the distinct phenological development of fruit trees compared to annual crops. Furthermore, C reserve dynamics of perennial deciduous trees were considered by adapting the $\mathrm{CN}$ allocation and typical management 
https://doi.org/10.5194/gmd-2022-41

Preprint. Discussion started: 16 February 2022

(c) Author(s) 2022. CC BY 4.0 License.

(c) (i)

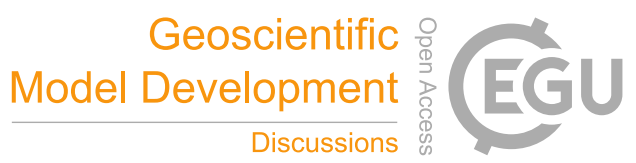

practices associated with fruit orchards were represented, such as transplanting of seedlings and winter pruning. To evaluate the development, a new apple PFT was parameterized, and the model was set up and tested using extensive site data of a mature apple orchard in Northern Italy.

One-by-one parameter sensitivity analysis revealed that photosynthetic parameters and parameters associated with canopy conductance have the highest influence on GPP, NEE, LE and yield, while phenological parameters were more influential in biomass partitioning to the different plant organs. Due to the high number of model parameters and parameter covariation, future studies could propose a more comprehensive sensitivity analysis with a training dataset consisting of multiple sites, which would give more insight into model sensitivity and could further improve the parameterization.

CLM-FruitTree was able to capture the seasonal biomass development as well as the average relative partitioning of the total biomass into the different plant organs. The inclusion of $\mathrm{C}$ reserves next to photosynthetic growth was imperative to enable regrowth at the end of a dormancy period and influenced LAI development, total seasonal biomass, and yield. Average simulated yield was within $2.3 \%$ of observation even though CLM-FruitTree showed a lower inter-annual variability likely due to the simplification of $\mathrm{C}$ reserve dynamics, specific management practices, and the alternate bearing behaviour exhibited by the Fuji apple cultivar.

The new phenology and $\mathrm{CN}$ allocation algorithms well represented the seasonal course of carbon, water, and energy fluxes of the orchard. The magnitude of ecosystem fluxes was particularly well captured for GPP, $\mathrm{R}_{\mathrm{n}}$, LE, and ET with correlation coefficients $>0.94$ and \%bias $< \pm 5 \%$. The model exhibited small biases in NEE and $R_{\text {eco }}$ that were most likely caused by the overestimation of $\mathrm{R}_{\mathrm{a}}$, especially leaf maintenance respiration. Possible reasons for the smaller simulated contribution of $\mathrm{R}_{\mathrm{s}}$ to $\mathrm{R}_{\text {eco }}$ could be the missing representation of the grass-covered alleys, differences in simulated and actual soil temperature or organic matter content, and oversimplification of microbial respiration processes. Additionally, large negative biases in simulated $\mathrm{H}$ were found over most of the main irrigation season during summer as the model simulated a strong evaporative cooling of the surface temperature.

585 Further model developments should consider the improvement of canopy processes related to energy partitioning and the inclusion of an active ground cover in the orchard representation to improve the yearly energy budget calculations and possibly soil respiration. An explicit representation of the microbial community and a more flexible calculation of $\mathrm{R}_{\mathrm{a}}$, i.e. considering tissue age, should also be the focus of future model improvements. In addition, management practices such as mowing or soil tillage could further enhance the model capability of capturing the dynamics and fate of assimilated C. Finally, the application of the newly developed sub-model to different geographical regions and other types of fruit trees or apple cultivars is needed to further validate the model and give more insight into the transferability of the development to different types of orchards. Overall, our results demonstrate the ability of the newly developed CLM-FruitTree sub-model to represent the seasonal dynamics and magnitudes of growth and ecosystem fluxes in a deciduous fruit orchard. As such, this development constitutes an important contribution towards a more comprehensive representation of the agricultural land surface in CLM5 by adding a perennial, woody crop to the existing annual crop types. This will allow for a more realistic evaluation of land use and climate 
change effects, or water availability at regional scale such as the Mediterranean or parts of China and the US, where perennial agriculture such as fruit orchards cover large parts of the agricultural landscape.

\section{Appendix}

\section{Appendix A: Sequential model for bud burst prediction}

The bud burst prediction in CLM-FruitTree is based on the sequential model developed by Cesaraccio et al. (2004). Negative chill days $\left(\mathrm{C}_{\mathrm{d}}\right)$ are accumulated from the $1^{\text {st }}$ of November followed by positive anti-chill days $\left(\mathrm{C}_{\mathrm{a}}\right)$ to overcome the different stages of tree dormancy, rest and quiescence. The chilling requirement $\left(C_{R}\right)$ defines the threshold for the accumulation of $C_{d}$ and is reached when $\sum C_{d} \leq C_{R}$. Thereafter $\mathrm{C}_{\mathrm{a}}$ accumulation begins until $C_{R}+\sum C_{a} \geq 0$ at which bud burst occurs. The accumulation of $C_{d}$ and $C_{a}$ on a given day is calculated from maximum $\left(T_{x}\right)$ and minimum ( $\left.T_{n}\right)$ daily air temperature as well as a temperature threshold for chill accumulation $\left(T_{C}\right)$, and varies depending on five possible temperature cases that relate $T_{x}$, $\mathrm{T}_{\mathrm{n}}, \mathrm{T}_{\mathrm{C}}$, and $0{ }^{\circ} \mathrm{C}$ with the daily mean air temperature (Table A1). The optimal values for $\mathrm{C}_{\mathrm{R}}$ and $\mathrm{T}_{\mathrm{C}}$ were calibrated based on bud burst observations from 2010-2013 for the Adige site by minimizing the RMSE between observations and predicted bud burst. The optimal value for $C_{R}$ was -68 while $T_{C}$ was $4{ }^{\circ} \mathrm{C}$ resulting in an RMSE of 7.2 days.

610 Table A1: Chill day $\left(\mathbf{C}_{\mathbf{d}}\right)$ and anti-chill day $\left(\mathbf{C}_{\mathbf{a}}\right)$ calculation for five different temperature cases relating maximum $\left(\mathbf{T}_{\mathbf{x}}\right)$ and minimum ( $\left.T_{n}\right)$ air temperature to the air temperature threshold $\left(T_{C}\right)$ and $0{ }^{\circ} \mathrm{C}, \mathbf{T}_{M}$ is the air mean temperature.

\begin{tabular}{ccc}
\hline Temperature Cases & Chill days & Anti-chill days \\
\hline $0 \leq T_{C} \leq T_{n} \leq T_{x}$ & $C_{d}=0$ & $C_{a}=T_{M}-T_{C}$ \\
$0 \leq T_{n} \leq T_{C}<T_{x}$ & $C_{d}=-\left[\left(T_{M}-T_{n}\right)-\frac{\left(T_{x}-T_{C}\right)^{2}}{2\left(T_{x}-T_{n}\right)}\right]$ & $C_{a}=\frac{\left(T_{x}-T_{C}\right)^{2}}{2\left(T_{x}-T_{n}\right)}$ \\
$0 \leq T_{n} \leq T_{x} \leq T_{C}$ & $C_{d}=-\left(T_{M}-T_{n}\right)$ & $C_{a}=0$ \\
$T_{n}<0 \leq T_{x} \leq T_{C}$ & $C_{d}=-\left[\frac{T_{x}^{2}}{2\left(T_{x}-T_{n}\right)}\right]$ & $C_{a}=0$ \\
$T_{n}<0<T_{C}<T_{x}$ & $C_{d}=-\frac{T_{x}^{2}}{2\left(T_{x}-T_{n}\right)}-\frac{\left(T_{x}-T_{C}\right)^{2}}{2\left(T_{x}-T_{n}\right)}$ & $C_{a}=\frac{\left(T_{x}-T_{C}\right)^{2}}{2\left(T_{x}-T_{n}\right)}$ \\
\hline
\end{tabular}

\section{Appendix B: Calculation of incoming longwave radiation}

Incoming longwave radiation $\left(\mathrm{LW}_{\text {in }}\right)$ can be expressed based on the Stefan Boltzmann Law as:

$$
L W_{\text {in }}=\varepsilon_{\text {eff }} * \sigma * T^{4}=\varepsilon_{c s} * F * \sigma * T^{4},
$$


https://doi.org/10.5194/gmd-2022-41

Preprint. Discussion started: 16 February 2022

(c) Author(s) 2022. CC BY 4.0 License.

(c) (i)

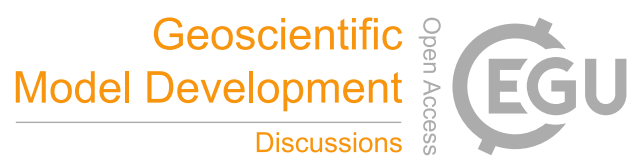

615 where $\varepsilon_{\text {eff }}$ is the effective emissivity that can be expressed by multiplying the clear-sky atmospheric emissivity $\varepsilon_{c s}$ with a cloud factor $F$ (always $\geq 1$ ) that expresses the increase of $L W_{i n}$ under cloudy conditions, $\sigma$ is the Stefan Boltzmann constant (5.67 x $10^{-8} \mathrm{~W} \mathrm{~m}^{-2} \mathrm{~K}^{-1}$ ) and $T$ is the $2 \mathrm{~m}$ air temperature in $\mathrm{K}$.

Clear-sky emissivity was obtained using the Konzelmann et al. (1994) parameterization as follows:

$$
\varepsilon_{c s}=0.23+0.484 *\left(\frac{e}{T}\right)^{\frac{1}{8}}
$$

where $e$ is the vapour pressure in $\mathrm{Pa}$ at $2 \mathrm{~m}$.

620 Equation (B1) can be rearranged to obtain $\mathrm{F}$ as follows:

$$
F=\frac{L W_{i n}}{\varepsilon_{c s} * \sigma * T^{4}}
$$

F was calculated at hourly interval using measured $\mathrm{LW}_{\text {in }}$ data from 2010 and $\varepsilon_{\mathrm{cs}}$ calculated using the above Eq. (B2).

As proposed by Sedlar and Hock (2009), in the absence of cloud data, the cloud factor F can be parameterized as a function of the atmospheric transmissivity index $\tau$, which is defined as follows:

$$
\tau=\frac{S W_{\text {in }}}{S W_{\text {toa }}},
$$

where $S W_{\text {in }}$ is the incoming shortwave radiation, and $S W_{\text {toa }}$ is the theoretical shortwave radiation received at the top of the atmosphere.

Figure B1 shows the linear equation that was fitted to the relationship of $\mathrm{F}$ and $\tau$ for the year 2010. For the calculation of clearsky emissivity, all data where $\tau$ was greater than 0.7 ( $\mathrm{N}=3863$ ) was considered based on the suggestion by Campbell (1985).

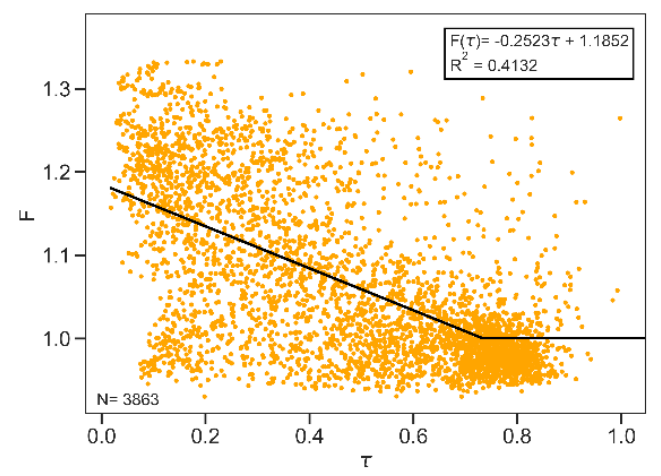

Figure B1: Cloud factor $F$ as a function of atmospheric emissivity $\tau$ for hourly observations. The black line represents the linear equation for $F(\tau)$ and $F \geq 1$. Clear-sky emissivity is parameterized based on Konzelmann et al. (1994).

For the nighttime values and for very low incoming shortwave radiation $\left(\mathrm{SW}_{\text {in }}<15 \mathrm{~W} \mathrm{~m}^{-2}\right), \tau$ was gap-filled with the mean of the two surrounding values to obtain a complete time series of $\mathrm{LW}_{\text {in }}$ data. Figure $\mathrm{B} 2$ shows the results of the $L W_{\text {in }}$ 
https://doi.org/10.5194/gmd-2022-41

Preprint. Discussion started: 16 February 2022

(c) Author(s) 2022. CC BY 4.0 License.

(c) (i)

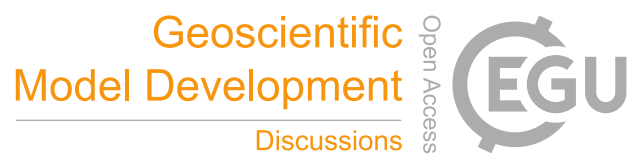

parameterization compared to $\mathrm{LW}_{\text {in }}$ calculated by CLM5 and to the observed data for the year 2010. As performance statistics the Pearson's r (r), the root mean square error (RMSE) and percent bias (\%bias) are given.
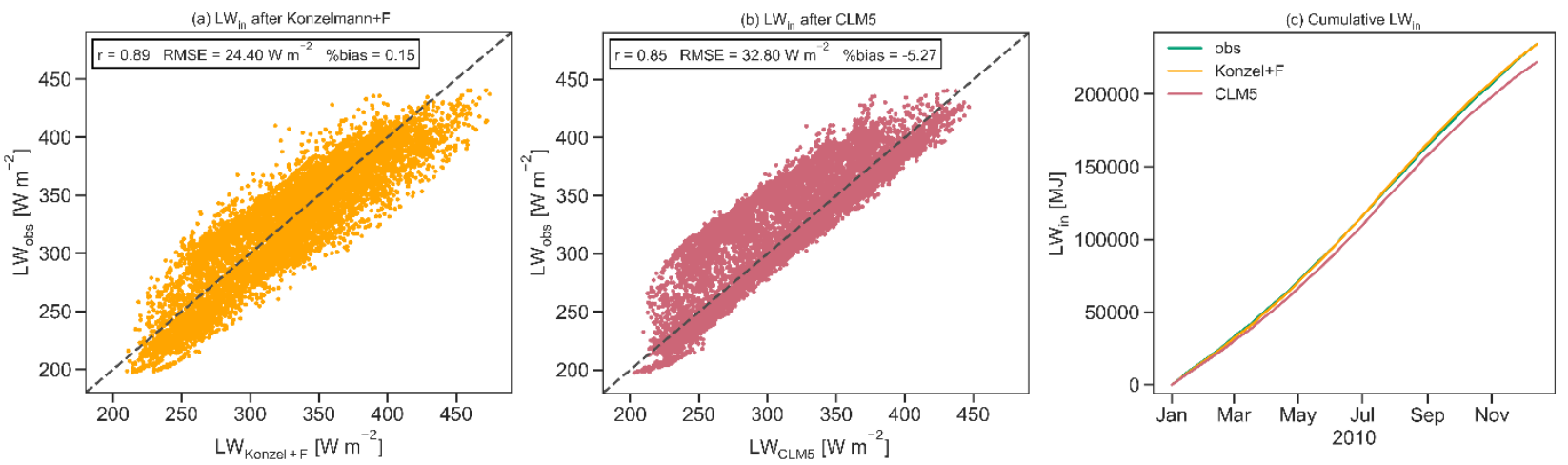

Figure B2: Comparison of observed $L W_{\text {in }}$ with the parameterization using (a) Konzelmann et al. (1994) according to Eq. (B2) and the cloud factor parameterization $\mathrm{F}(\tau)$, and (b) the calculation procedure used in CLM5, as well as (c) cumulative observed and calculated $\mathbf{L}$ in for 2010. Pearson's r, RMSE and \%bias are given as performance statistics. 


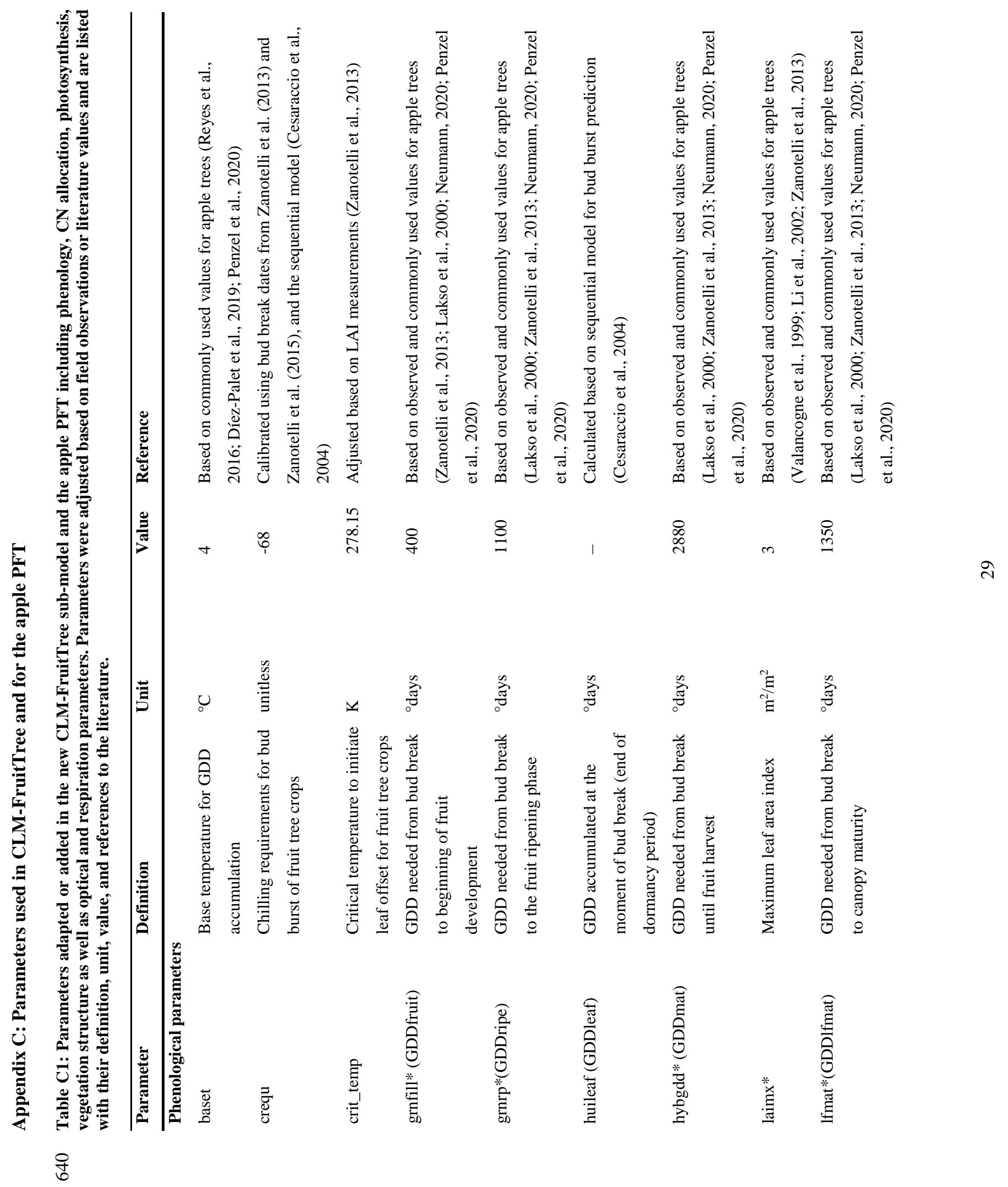


ळ̆

$\stackrel{n}{0} \stackrel{2}{\circ}$

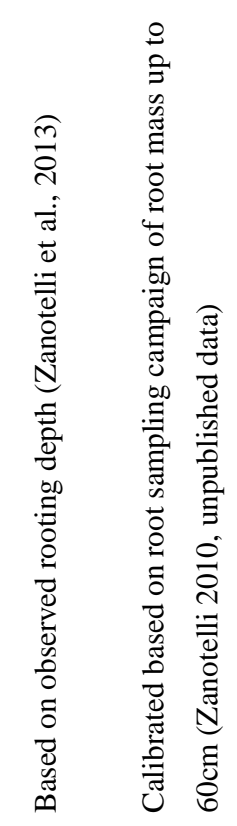

in $\quad-\infty$

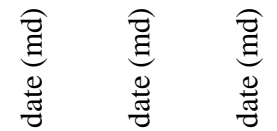<smiles>[13CH3]</smiles>

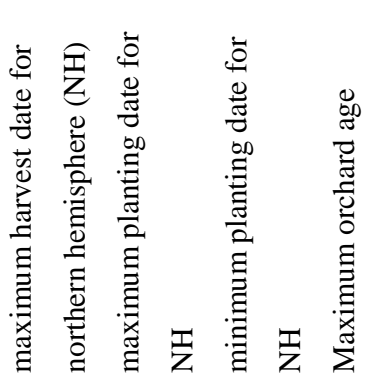

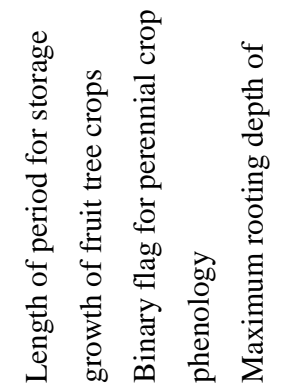

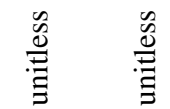

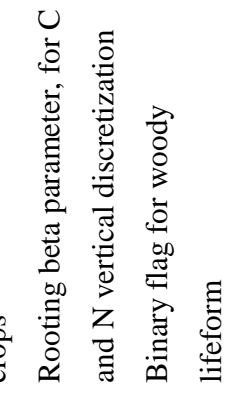

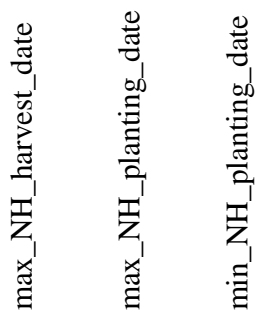

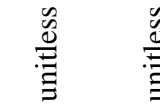

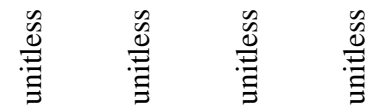

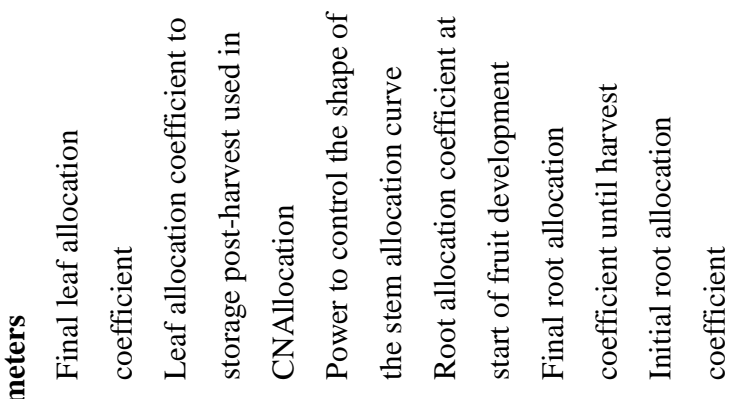



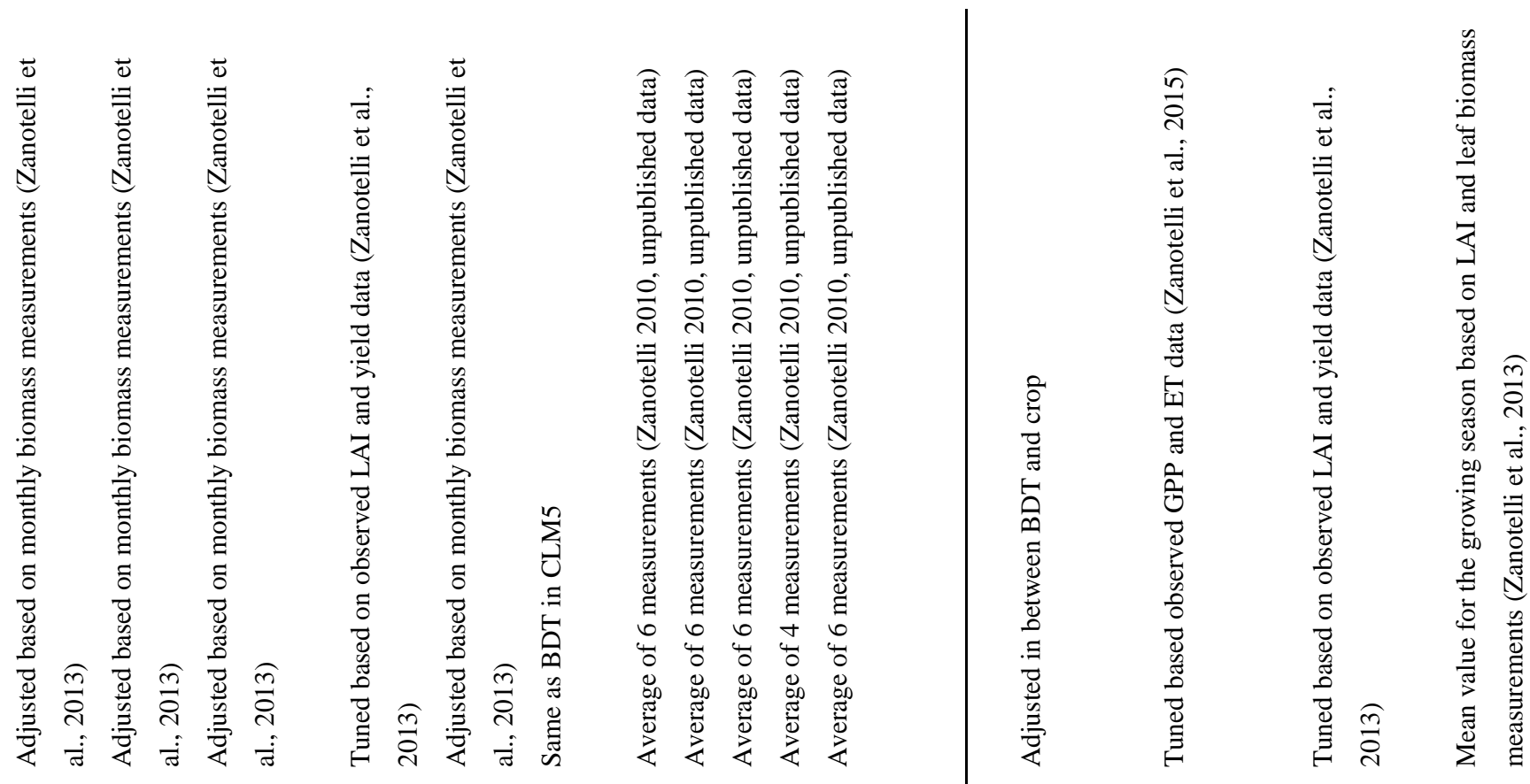

สุ

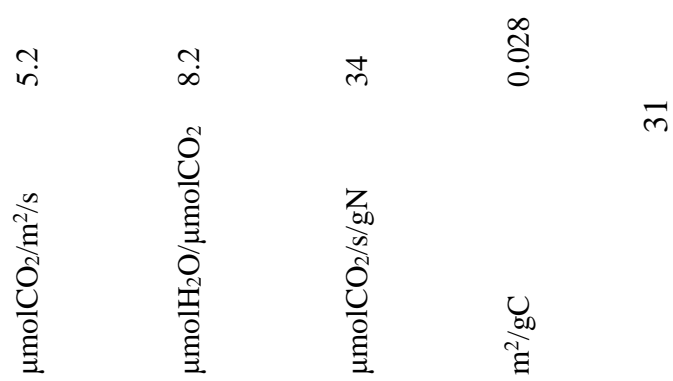

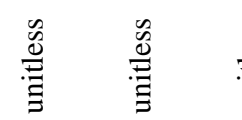

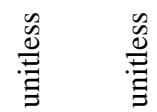

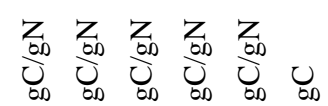

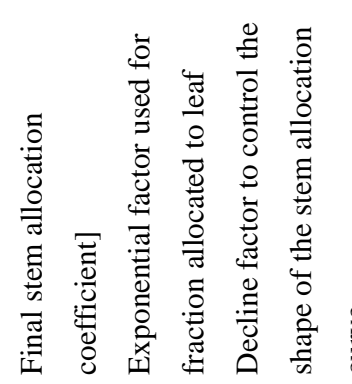

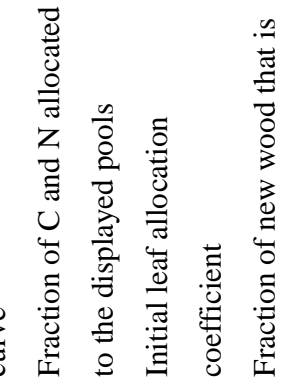

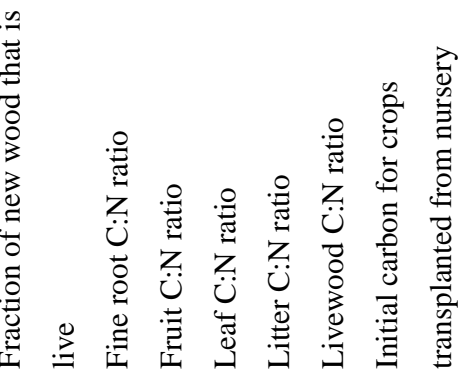

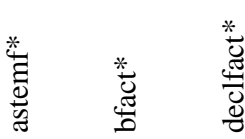

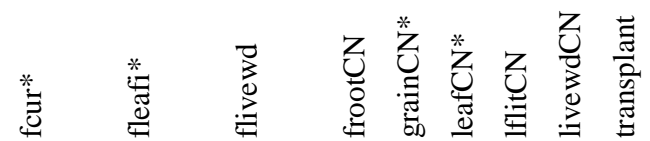

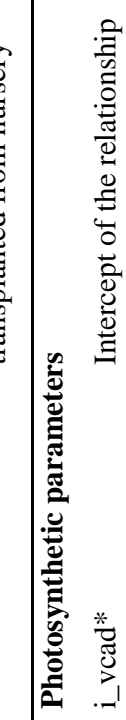

章

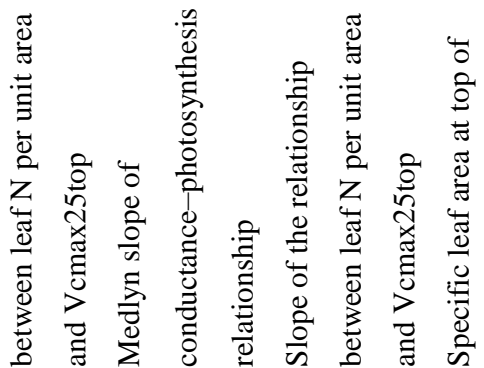

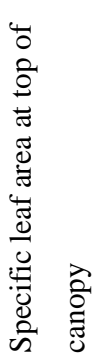


https://doi.org/10.5194/gmd-2022-41

Preprint. Discussion started: 16 February 2022

(c) Author(s) 2022. CC BY 4.0 License.

(c) (i)

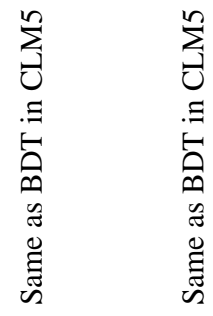

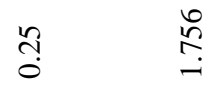


Code availability: The new sub-model CLM-FruitTree is freely available via Zenodo, https://doi.org/10.5281/zenodo.6025014

Author contribution: OD developed and modified the code for the sub-model; designed, performed, and analysed the simulations; and prepared the original draft of the manuscript. HB, HJHF, and CB supervised the research, and, together with DZ contributed to the manuscript writing through review \& editing.

Competing interests: The authors declare no conflict of interest.

650 Acknowledgements: The authors gratefully acknowledge Damiano Zanotelli and his team for providing the field data of the apple orchard in the South Tyrol, Italy. The authors thank Yuanchao Fan for sharing the source files for his development of CLM-Palm (Fan et al., 2015) that aided the development of the new sub-model CLM-FruitTree. Furthermore, the authors thank Martin Thalheimer for providing the meteorological data from Laimburg meteorological station. This research was supported by the ATLAS project funded by the European Union's Horizon 2020 research and innovation programme under grant agreement No. 857125. Lastly, Harrie-Jan Hendricks Franssen acknowledges support from the Deutsche Forschungsgemeinschaft under Germany’s Excellence Strategy, EXC-2070-390732324-PhenoRob.

\section{References}

Aguilera, E., Guzmán, G., and Alonso, A.: Greenhouse gas emissions from conventional and organic cropping systems in Spain. II. Fruit tree orchards, Agronomy for Sustainable Development, 35, 725-737, https://doi.org/10.1007/s13593-014-0265-y, 2015.

Allen, M., Prusinkiewicz, P., and DeJong, T.: Using L-systems for modeling source-sink interactions, architecture and physiology of growing trees: the L-PEACH model, New phytologist, 166, 869-880, https://doi.org/10.1111/j.1469-8137.2005.01348.x, 2005.

Anderson, J., Richardson, E., and Kesner, C.: Validation of chill unit and flower bud phenology models for 'Montmorency' sour cherry, I International Symposium on Computer Modelling in Fruit Research and Orchard Management 184, 71-78, https://doi.org/10.17660/ActaHortic.1986.184.7, 1985.

Atay, A. N., Koyuncu, F., and Atay, E.: Relative susceptibility of selected apple cultivars to alternate bearing, Journal of Biological and Environmental Sciences, 7, 81-86, 2013.

Balsamo, G., Beljaars, A., Scipal, K., Viterbo, P., van den Hurk, B., Hirschi, M., and Betts, A. K.: A revised hydrology for the ECMWF model: Verification from field site to terrestrial water storage and impact in the Integrated Forecast System, Journal of hydrometeorology, 10, 623-643, https://doi.org/10.1175/2008JHM1068.1, 2009.

Bastías, R. M. and Corelli-Grappadelli, L.: Light quality management in fruit orchards: physiological and technological aspects, Chilean Journal of Agricultural Research, 72, 574, 2012.

Belleggia, A., Murri, G., and Neri, D.: Crop load control of 'Fuji' apple in central Italy, XI International Symposium on Plant Bioregulators in Fruit Production 884, 399-405, https://doi.org/10.17660/ActaHortic.2010.884.48, 2009.

Benyei, P., Cohen, M., Gresillon, E., Angles, S., Araque-Jiménez, E., Alonso-Roldán, M., and Espadas-Tormo, I.: Pruning waste management and climate change in Sierra Mágina's olive groves (Andalusia, Spain), Regional environmental change, 18, 595-605, https://doi.org/10.1007/s10113-017-1230-5, 2018.

Bepete, M. and Lakso, A.: Apple fruit respiration in the field: relationships to fruit growth rate, temperature, and light exposure, VI International Symposium on Integrated Canopy, Rootstock, Environmental Physiology in Orchard Systems 451, 319-326, https://doi.org/10.17660/ActaHortic.1997.451.37, 1996.

680 Blyth, E. M., Arora, V. K., Clark, D. B., Dadson, S. J., De Kauwe, M. G., Lawrence, D. M., Melton, J. R., Pongratz, J., Turton, R. H., and Yoshimura, K.: Advances in land surface modelling, Current Climate Change Reports, 7, 45-71, https://doi.org/10.1007/s40641-021$00171-5,2021$.

Boas, T., Bogena, H., Grünwald, T., Heinesch, B., Ryu, D., Schmidt, M., Vereecken, H., Western, A., and Hendricks Franssen, H.-J.: Improving the representation of cropland sites in the Community Land Model (CLM) version 5.0, Geoscientific Model Development, 14, 573-601, https://doi.org/10.5194/gmd-14-573-2021, 2021.

Bollard, E.: Transport in the xylem, Annual Review of Plant Physiology, 11, 141-166, 1960.

Bryś, K., Bryś, T., and Ojrzyńska, H.: Long-wave radiation balances of grassy surface and bare soil in Wrocław, E3S Web of Conferences, 1-8, https://doi.org/10.1051/e3sconf/201911600012, 2019.

Bwalya, J. M.: Estimation of net carbon sequestration potential of citrus under different management systems using the life cycle approach, M.S. thesis, University of Zambia, http://thesisbank.jhia.ac.ke/id/eprint/8503, 2012.

Campbell, G. S.: Soil physics with BASIC: transport models for soil-plant systems, Elsevier, Washington, U.S., 1985. 
Carranca, C., Brunetto, G., and Tagliavini, M.: Nitrogen nutrition of fruit trees to reconcile productivity and environmental concerns, Plants, 7, 1-12, https://doi.org/10.3390/plants7010004, 2018.

Cesaraccio, C., Spano, D., Snyder, R. L., and Duce, P.: Chilling and forcing model to predict bud-burst of crop and forest species, Agricultural and Forest Meteorology, 126, 1-13, https://doi.org/10.1016/j.agrformet.2004.03.002, 2004.

Cheng, Y., Huang, M., Chen, M., Guan, K., Bernacchi, C., Peng, B., and Tan, Z.: Parameterizing perennial bioenergy crops in Version 5 of the Community Land Model based on site-level observations in the Central Midwestern United States, Journal of Advances in Modeling Earth Systems, 12, 1-24, https://doi.org/10.1029/2019MS001719, 2020.

Chmielewski, F.-M., Blümel, K., and Pálešová, I.: Climate change and shifts in dormancy release for deciduous fruit crops in Germany, Climate research, 54, 209-219, https://doi.org/10.3354/cr01115, 2012.

Corelli-Grappadelli, L. and Lakso, A. N.: Fruit development in deciduous tree crops as affected by physiological factors and environmental conditions (keynote), XXVI International Horticultural Congress: Key Processes in the Growth and Cropping of Deciduous Fruit and Nut Trees 636, 425-441, https://doi.org/10.17660/ActaHortic.2004.636.52, 2002.

Corelli-Grappadelli, L. and Marini, R.: 11 Orchard Planting Systems, in: The peach: botany, production and uses, CABI, Pennsylvania, U.S., 264, 2008

Dagon, K., Sanderson, B. M., Fisher, R. A., and Lawrence, D. M.: A machine learning approach to emulation and biophysical parameter estimation with the Community Land Model, version 5, Advances in Statistical Climatology, Meteorology and Oceanography, 6, 223244, https://doi.org/10.5194/ascmo-6-223-2020, 2020.

DeJong, T. M. and Grossman, Y. L.: A supply and demand approach to modeling annual reproductive and vegetative growth of deciduous fruit trees, HortScience, 29, 1435-1442, 1994.

Díez-Palet, I., Funes, I., Savé, R., Biel, C., de Herralde, F., Miarnau, X., Vargas, F., Àvila, G., Carbó, J., and Aranda, X.: Blooming under Mediterranean climate: Estimating cultivar-specific chill and heat requirements of almond and apple trees using a statistical approach, Agronomy, 9, 760-781, https://doi.org/10.3390/agronomy9110760, 2019.

715 hombrowski, O.: odombro/CTSM: CLM-

El Jaouhari, N., Abouabdillah, A., Bouabid, R., Bourioug, M., Aleya, L., and Chaoui, M.: Assessment of sustainable deficit irrigation in a Moroccan apple orchard as a climate change adaptation strategy, Science of the total environment, 642, 574-581, https://doi.org/10.1016/j.scitotenv.2018.06.108, 2018.

Fader, M., von Bloh, W., Shi, S., Bondeau, A., and Cramer, W.: Modelling Mediterranean agro-ecosystems by including agricultural trees in the LPJmL model, Geoscientific Model Development, 8, 3545-3561, https://doi.org/10.5194/gmd-8-3545-2015, 2015.

Fan, Y., Roupsard, O., Bernoux, M., Le Maire, G., Panferov, O., Kotowska, M. M., and Knohl, A.: A sub-canopy structure for simulating oil palm in the Community Land Model (CLM-Palm): phenology, allocation and yield, Geoscientific Model Development, 8, 37853800, https://doi.org/10.5194/gmd-8-3785-2015, 2015.

FAO Crops and livestock products: https://www.fao.org/faostat/en/\#data/QCL, last access: 22 December 2021.

725 Faust, M., Erez, A., Rowland, L. J., Wang, S. Y., and Norman, H. A.: Bud dormancy in perennial fruit trees: physiological basis for dormancy induction, maintenance, and release, HortScience, 32, 623-629, 1997.

Fisher, R. A. and Koven, C. D.: Perspectives on the future of land surface models and the challenges of representing complex terrestrial systems, Journal of Advances in Modeling Earth Systems, 12, 1-24, https://doi.org/10.1029/2018MS001453, 2020.

Glover, J. D., Reganold, J., Bell, L., Borevitz, J., Brummer, E., Buckler, E. S., Cox, C., Cox, T. S., Crews, T., and Culman, S.: Increased food and ecosystem security via perennial grains, Science, 328, 1638-1639, https://doi.org/10.1126/science.1188761, 2010.

Göhler, M., Mai, J., and Cuntz, M.: Use of eigendecomposition in a parameter sensitivity analysis of the Community Land Model, Journal of Geophysical Research: Biogeosciences, 118, 904-921, https://doi.org/10.1002/jgrg.20072, 2013.

Goldschmidt, E. E. and Lakso, A. N.: Fruit tree models: scope and limitations, Information and Communication Technology (ICT) Development and Adoption: Perspectives of Technological Innovation, 1-19, 2005.

735 Grechi, I., Sauge, M. H., Sauphanor, B., Hilgert, N., Senoussi, R., and Lescourret, F.: How does winter pruning affect peach tree-Myzus persicae interactions?, Entomologia Experimentalis et Applicata, 128, 369-379, https://doi.org/10.1111/j.1570-7458.2008.00720.x, 2008.

Greer, D. H., Wünsche, J. N., and Halligan, E. A.: Influence of postharvest temperatures on leaf gas exchange, carbohydrate reserves and allocations, subsequent budbreak, and fruit yield of 'Braeburn'apple (Malus domestica) trees, New Zealand Journal of Crop and Horticultural Science, 30, 175-185, https://doi.org/10.1080/01140671.2002.9514213, 2002.

Hammad, H. M., Nauman, H. M. F., Abbas, F., Ahmad, A., Bakhat, H. F., Saeed, S., Shah, G. M., Ahmad, A., and Cerdà, A.: Carbon sequestration potential and soil characteristics of various land use systems in arid region, Journal of environmental management, 264, 110254, https://doi.org/10.1016/j.jenvman.2020.110254, 2020.

Heide, O. M. and Prestrud, A. K.: Low temperature, but not photoperiod, controls growth cessation and dormancy induction and release in apple and pear, Tree physiology, 25, 109-114, https://doi.org/10.1093/treephys/25.1.109, 2005. 
Hou, T., Wang, Y., Guo, F., Jia, Q., Wu, X., Wang, E., and Hong, J.: Soil Respiration Characteristics and Influencing Factors for Apple Orchards in Different Regions on the Loess Plateau of Shaanxi Province, Sustainability, 13, 1-21, https://doi.org/10.3390/su13094780, 2021.

Idso, S. B.: A set of equations for full spectrum and 8-to $14-\mu \mathrm{m}$ and 10.5-to 12.5- $\mu \mathrm{m}$ thermal radiation from cloudless skies, Water resources research, 17, 295-304, https://doi.org/10.1029/WR017i002p00295, 1981.

Jackson, D.: Flowers and fruit, in: Temperate and subtropical fruit production., CABI, Cambridge, U.K., 34-43, 2011.

Kazimierski, P., Hercel, P., Suchocki, T., Smoliński, J., Pladzyk, A., Kardaś, D., Łuczak, J., and Januszewicz, K.: Pyrolysis of Pruning Residues from Various Types of Orchards and Pretreatment for Energetic Use of Biochar, Materials, 14, 1-14, https://doi.org/10.3390/ma14112969, 2021.

Konzelmann, T., van de Wal, R. S., Greuell, W., Bintanja, R., Henneken, E. A., and Abe-Ouchi, A.: Parameterization of global and longwave incoming radiation for the Greenland Ice Sheet, Global and Planetary change, 9, 143-164, https://doi.org/10.1016/0921-8181(94)90013$2,1994$.

Kozlowski, T.: Carbohydrate sources and sinks in woody plants, The botanical review, 58, 107-222, 1992.

Krinner, G., Viovy, N., de Noblet-Ducoudré, N., Ogée, J., Polcher, J., Friedlingstein, P., Ciais, P., Sitch, S., and Prentice, I. C.: A dynamic global vegetation model for studies of the coupled atmosphere-biosphere system, Global Biogeochemical Cycles, 19, 1-33, https://doi.org/10.1029/2003GB002199, 2005.

la Fuente-Sáiz, D., Ortega-Farías, S., Fonseca, D., Ortega-Salazar, S., Kilic, A., and Allen, R.: Calibration of METRIC model to estimate energy balance over a drip-irrigated apple orchard, Remote Sensing, 9, 1-18, https://doi.org/10.3390/rs9070670, 2017.

Lakso, A., White, M., and Tustin, D.: Simulation modeling of the effects of short and long-term climatic variations on carbon balance of apple trees, VII International Symposium on Orchard and Plantation Systems 557, 473-480, https://doi.org/10.17660/ActaHortic.2001.557.63, 2000.

Lakso, A., Wunsche, J., Palmer, J., and Grappadelli, L. C.: Measurement and modeling of carbon balance of the apple tree, HortScience, 34 , 1040-1047, 1999.

Lasslop, G., Migliavacca, M., Bohrer, G., Reichstein, M., Bahn, M., Ibrom, A., Jacobs, C., Kolari, P., Papale, D., and Vesala, T.: On the choice of the driving temperature for eddy-covariance carbon dioxide flux partitioning, Biogeosciences, 9, 5243-5259, https://doi.org/10.5194/bg-9-5243-2012, 2012.

Lawrence, D., Fisher, R., Koven, C., Oleson, K., Swenson, S., Vertenstein, M., Andre, B., Bonan, G., Ghimire, B., and van Kampenhout, L.: Technical description of version 5.0 of the Community Land Model (CLM), Natl. Cent. Atmospheric Res. (NCAR), available at: http://www.cesm.ucar.edu/models/cesm2/land/CLM50_Tech_Note.pdf (last access: 2 May 2021), 2018.

775 Le Roux, X., Lacointe, A., Escobar-Gutiérrez, A., and Le Dizès, S.: Carbon-based models of individual tree growth: a critical appraisal, Annals of Forest Science, 58, 469-506, https://doi.org/10.1051/forest:2001140, 2001.

Ledo, A., Smith, P., Zerihun, A., Whitaker, J., Vicente-Vicente, J. L., Qin, Z., McNamara, N. P., Zinn, Y. L., Llorente, M., and Liebig, M.: Changes in soil organic carbon under perennial crops, Global change biology, 26, 4158-4168, https://doi.org/10.1111/gcb.15120, 2020.

Li, F., Cohen, S., Naor, A., Shaozong, K., and Erez, A.: Studies of canopy structure and water use of apple trees on three rootstocks, Agricultural Water Management, 55, 1-14, https://doi.org/10.1016/S0378-3774(01)00184-6, 2002.

Lobianco, A. and Roberto, E.: The regional model for Mediterranean agriculture, Munich Personal RePEc Archive (MPRA), Munich, Germany, IDEMA DELIVERABLE No. 17, 2006.

Loescher, W. H., McCamant, T., and Keller, J. D.: Carbohydrate reserves, translocation, and storage in woody plant roots, HortScience, 25, 274-281, 1990.

785 López-Olivari, R., Ortega-Farías, S., and Poblete-Echeverría, C.: Partitioning of net radiation and evapotranspiration over a superintensive drip-irrigated olive orchard, Irrigation science, 34, 17-31, https://doi.org/10.1007/s00271-015-0484-2, 2016.

Luo, Q., Wen, J., Hu, Z., Lu, Y., and Yang, X.: Parameter sensitivities of the Community Land Model at two alpine sites in the three-river source region, Journal of Meteorological Research, 34, 851-864, https://doi.org/10.1007/s13351-020-9205-8, 2020.

Maestre-Valero, J. F., Testi, L., Jiménez-Bello, M. A., Castel, J. R., and Intrigliolo, D. S.: Evapotranspiration and carbon exchange in a citrus orchard using eddy covariance, Irrigation Science, 35, 397-408, https://doi.org/10.1007/s00271-017-0548-6, 2017.

Martin-Gorriz, B., González-Real, M. M., Egea, G., and Baille, A.: Ecosystem respiration of old and young irrigated citrus orchards in a semiarid climate, Agricultural and Forest Meteorology, 280, 1-15, https://doi.org/10.1016/j.agrformet.2019.107787, 2020.

Millard, P.: Ecophysiology of the internal cycling of nitrogen for tree growth, Zeitschrift für Pflanzenernährung und Bodenkunde, 159, 110, https://doi.org/10.1002/jpln.1996.3581590102, 1996.

795 Montagnani, L., Zanotelli, D., Tagliavini, M., and Tomelleri, E.: Timescale effects on the environmental control of carbon and water fluxes of an apple orchard, Ecology and evolution, 8, 416-434, https://doi.org/10.1002/ece3.3633, 2018.

Montanaro, G., Celano, G., Dichio, B., and Xiloyannis, C.: Effects of soil-protecting agricultural practices on soil organic carbon and productivity in fruit tree orchards, Land Degradation \& Development, 21, 132-138, https://doi.org/10.1002/ldr.917, 2010.

Murneek, A. E.: Quantitative distribution of nitrogen and carbohydrates in apple trees, University of Missouri, College of Agriculture, Missouri, U.S., 1-28, 1942. 
Musacchi, S. and Serra, S.: Apple fruit quality: Overview on pre-harvest factors, Scientia Horticulturae, 234, 409-430, https://doi.org/10.1016/j.scienta.2017.12.057, 2018.

Neumann, L.: Improving the apple carbon balance model MaluSim by integrating and testing water deficit and fruit drop effects, M.A. thesis, Hannover: Institutionelles Repositorium der Leibniz Universität Hannover, Hannover, Germany, 147 pp., https://doi.org/10.15488/10194, 2020.

Noilhan, J. and Mahfouf, J.-F.: The ISBA land surface parameterisation scheme, Global and planetary Change, 13, 145-159, https://doi.org/10.1016/0921-8181(95)00043-7, 1996.

Ntshidi, Z., Dzikiti, S., Mazvimavi, D., and Mobe, N.: Contribution of understorey vegetation to evapotranspiration partitioning in apple orchards under Mediterranean climatic conditions in South Africa, Agricultural Water Management, 245, 1-11, https://doi.org/10.1016/j.agwat.2020.106627, 2021.

O'Connell, M. and Scalisi, A.: Sensing fruit and tree performance under deficit irrigation in 'September Bright' nectarine, International Symposium on Precision Management of Orchards and Vineyards 1314, 9-16, https://doi.org/10.17660/ActaHortic.2021.1314.2, 2019.

Oliveira, C. M. and Priestley, C. A.: Carbohydrate reserves in deciduous fruit trees, Hort. Rev, 10, 403-430, 1988.

Oorthuis, R., Vaunat, J., Hürlimann, M., Lloret, A., Moya, J., Puig-Polo, C., and Fraccica, A.: Slope orientation and vegetation effects on soil thermo-hydraulic behavior. An experimental study, Sustainability, 13, 1-14, https://doi.org/10.3390/su13010014, 2021.

Pallas, B., Da Silva, D., Valsesia, P., Yang, W., Guillaume, O., Lauri, P.-E., Vercambre, G., Génard, M., and Costes, E.: Simulation of carbon allocation and organ growth variability in apple tree by connecting architectural and source-sink models, Annals of Botany, 118, 317-330, https://doi.org/10.1093/aob/mcw085, 2016.

Pasa, M. d. S., Carra, B., Brighenti, A. F., Pinto, F. A. M. F., Mello-Farias, P. C. d., and Herter, F. G.: Ethephon as a potential tool to manage alternate bearing of 'Fuji' apple trees, Revista Ceres, 68, 180-184, https://doi.org/10.1590/0034-737X202168030003, 2021.

Penzel, M., Lakso, A. N., Tsoulias, N., and Zude-Sasse, M.: Carbon consumption of developing fruit and the fruit bearing capacity of individual RoHo 3615 and Pinova apple trees, Int. Agrophys., 34, 409-423, https://doi.org/10.31545/intagr/127540, 2020.

Prentice, I. C., Liang, X., Medlyn, B. E., and Wang, Y.-P.: Reliable, robust and realistic: the three R's of next-generation land-surface modelling, Atmospheric Chemistry and Physics, 15, 5987-6005, https://doi.org/10.5194/acp-15-5987-2015, 2015.

Reichstein, M., Falge, E., Baldocchi, D., Papale, D., Aubinet, M., Berbigier, P., Bernhofer, C., Buchmann, N., Gilmanov, T., and Granier, A.: On the separation of net ecosystem exchange into assimilation and ecosystem respiration: review and improved algorithm, Global change biology, 11, 1424-1439, https://doi.org/10.1111/j.1365-2486.2005.001002.x, 2005.

Reyes, F., DeJong, T., Franceschi, P., Tagliavini, M., and Gianelle, D.: Maximum growth potential and periods of resource limitation in apple tree, Frontiers in Plant Science, 7, 1-12, https://doi.org/10.3389/fpls.2016.00233, 2016.

830 Sanchez, E. E., Khemira, H., Sugar, D., and Righetti, T. L.: Nitrogen management in orchards, in: Nitrogen Fertilization in the Environment, Marcel Dekker, Inc., New York, U.S., 1995.

Scandellari, F., Caruso, G., Liguori, G., Meggio, F., Palese, A. M., Zanotelli, D., Celano, G., Gucci, R., Inglese, P., and Pitacco, A.: A survey of carbon sequestration potential of orchards and vineyards in Italy, European Journal of Horticultural Science, 81, 106-114, https://doi.org/10.17660/eJHS.2016/81.2.4, 2016.

Schaphoff, S., von Bloh, W., Rammig, A., Thonicke, K., Biemans, H., Forkel, M., Gerten, D., Heinke, J., Jägermeyr, J., and Knauer, J.: LPJmL4-a dynamic global vegetation model with managed land-Part 1: Model description, Geoscientific Model Development, 11, 1343-1375, https://doi.org/10.5194/gmd-2017-145, 2018.

Sedlar, J. and Hock, R.: Testing longwave radiation parameterizations under clear and overcast skies at Storglaciären, Sweden, The Cryosphere, 3, 75-84, https://doi.org/10.5194/tc-3-75-2009, 2009.

840 Segovia-Cardozo, D. A., Franco, L., and Provenzano, G.: Detecting crop water requirement indicators in irrigated agroecosystems from soil water content profiles: An application for a citrus orchard, Science of The Total Environment, 806, https://doi.org/10.1016/j.scitotenv.2021.150492, 2022.

Song, J., Miller, G. R., Cahill, A. T., Aparecido, L. M. T., and Moore, G. W.: Modeling land surface processes over a mountainous rainforest in Costa Rica using CLM4. 5 and CLM5, Geoscientific Model Development, 13, 5147-5173, https://doi.org/10.5194/gmd-13-51472020, 2020.

Tanny, J. and Cohen, S.: The effect of a small shade net on the properties of wind and selected boundary layer parameters above and within a citrus orchard, Biosystems Engineering, 84, 57-67, https://doi.org/10.1016/S1537-5110(02)00233-7, 2003.

Tomè, E., Ventura, M., Folegot, S., Zanotelli, D., Montagnani, L., Mimmo, T., Tonon, G., Tagliavini, M., and Scandellari, F.: Mycorrhizal contribution to soil respiration in an apple orchard, Applied Soil Ecology, 101, 165-173, https://doi.org/10.1016/j.apsoil.2016.01.016, 2016.

Tromp, J.: Nutrient reserves in roots of fruit trees, in particular carbohydrates and nitrogen, Plant and Soil, 71, 401-413, https://doi.org/10.1007/BF02182682, 1983.

Turrini, A., Caruso, G., Avio, L., Gennai, C., Palla, M., Agnolucci, M., Tomei, P. E., Giovannetti, M., and Gucci, R.: Protective green cover enhances soil respiration and native mycorrhizal potential compared with soil tillage in a high-density olive orchard in a long term study, Applied Soil Ecology, 116, 70-78, https://doi.org/10.1016/j.apsoil.2017.04.001, 2017. 
Valancogne, C., Dayau, S., Pieri, P., Ferreira, M. I., Silvestre, J., and Angelocci, L.: Influence of orchard and vineyard characteristics on maximal plant transpiration, 3. International symposium on irrigation of Horticultural crops, Lisbonne, Portugal, https://hal.inrae.fr/hal$02770605,1999$.

Viovy, N.: CRUNCEP Version 7 - Atmospheric Forcing Data for the Community Land Model, Research Data Archive at the National Center for Atmospheric Research, Computational and Information Systems Laboratory, https://doi.org/10.5065/PZ8F-F017, 2018.

Wheaton, T., Castle, W., Whitney, J., Tucker, D., and Muraro, R.: A high density citrus planting, Proc. Fla. State Hort. Soc, Florida, U.S., 55-59, 1990.

Wu, T., Wang, Y., Yu, C., Chiarawipa, R., Zhang, X., Han, Z., and Wu, L.: Carbon sequestration by fruit trees-Chinese apple orchards as an example, PLoS one, 7, 1-13, https://doi.org/10.1371/journal.pone.0038883, 2012.

865 Wünsche, J. N. and Lakso, A. N.: Apple tree physiology-implications for orchard and tree management, Compact Fruit Tree, 33, 82-88, 2000.

Yasin, G., Farrakh Nawaz, M., Zubair, M., Qadir, I., Saleem, A. R., Ijaz, M., Gul, S., Amjad Bashir, M., Rehim, A., and Rahman, S. U.: Assessing the Contribution of Citrus Orchards in Climate Change Mitigation through Carbon Sequestration in Sargodha District, Pakistan, Sustainability, 13, 1-10, https://doi.org/10.3390/su132212412, 2021.

870 Zanotelli, D., Montagnani, L., Andreotti, C., and Tagliavini, M.: Evapotranspiration and crop coefficient patterns of an apple orchard in a sub-humid environment, Agricultural Water Management, 226, 1-11, https://doi.org/10.1016/j.agwat.2019.105756, 2019.

Zanotelli, D., Montagnani, L., Manca, G., and Tagliavini, M.: Net primary productivity, allocation pattern and carbon use efficiency in an apple orchard assessed by integrating eddy covariance, biometric and continuous soil chamber measurements, Biogeosciences, 10, 30893108, https://doi.org/10.5194/bg-10-3089-2013, 2013.

875 Zanotelli, D., Montagnani, L., Manca, G., Scandellari, F., and Tagliavini, M.: Net ecosystem carbon balance of an apple orchard, European Journal of Agronomy, 63, 97-104, http://dx.doi.org/10.1016/j.eja.2014.12.002, 2015.

Zavalloni, C., Andresen, J. A., and Flore, J.: Phenological Models of Flower Bud Stages and Fruit Growth ofMontmorency'Sour Cherry Based on Growing Degree-day Accumulation, Journal of the American Society for Horticultural Science, 131, 601-607, https://doi.org/10.21273/JASHS.131.5.601, 2006.

880 Zeng, Y., Xie, Z., and Liu, S.: Seasonal effects of irrigation on land-atmosphere latent heat, sensible heat, and carbon fluxes in semiarid basin, Earth System Dynamics, 8, 113-127, https://doi.org/10.5194/esd-8-113-2017, 2017. 